\title{
INEQUALITY OF EDUCATIONAL OPPORTUNITY? SCHOOLS AS MEDIATORS OF THE INTERGENERATIONAL TRANSMISSION OF INCOME
}

\author{
Jesse Rothstein \\ Working Paper 24537 \\ http://www.nber.org/papers/w24537 \\ NATIONAL BUREAU OF ECONOMIC RESEARCH \\ 1050 Massachusetts Avenue \\ Cambridge, MA 02138 \\ April 2018
}

I thank Audrey Tiew, Leah Shiferaw, Julien Lafortune, and Rachel Young for excellent research assistance as well as Charlie Brown, David Card, Avi Feller, Pat Kline, and conference and seminar participants at NBER, NYU, SOLE, UC Irvine, UC Riverside, UCSB, UCSD, UQAM, and the Trans-Pacific Labor Seminar for helpful discussions and comments. I am grateful to the Russell Sage Foundation for financial support. The views expressed herein are those of the author and do not necessarily reflect the views of the National Bureau of Economic Research.

NBER working papers are circulated for discussion and comment purposes. They have not been peer-reviewed or been subject to the review by the NBER Board of Directors that accompanies official NBER publications.

(C) 2018 by Jesse Rothstein. All rights reserved. Short sections of text, not to exceed two paragraphs, may be quoted without explicit permission provided that full credit, including () notice, is given to the source. 
Inequality of Educational Opportunity? Schools as Mediators of the Intergenerational Transmission of Income

Jesse Rothstein

NBER Working Paper No. 24537

April 2018

JEL No. I24,I3,J12,J24

\begin{abstract}
$\underline{\text { ABSTRACT }}$
Chetty et al. (2014b) show that children from low-income families achieve higher adult incomes, relative to those from higher income families, in some commuting zones $(\mathrm{CZs})$ than in others. I investigate whether children's educational outcomes help to explain the between-CZ differences. I find little evidence that the quality of schools is a key mechanism driving variation in intergenerational mobility. While $\mathrm{CZs}$ with stronger intergenerational income transmission have somewhat stronger transmission of parental income to children's educational attainment and achievement, on average, neither can explain a large share of the between- $\mathrm{CZ}$ variation. Marriage patterns explain two-fifths of the variation in income transmission, human capital accumulation and returns to human capital each explain only one-ninth, and the remainder of the variation (about one-third) reflects differences in earnings between children from high- and low-income families that are not mediated by human capital. This points to job networks and the structure of local labor and marriage markets, rather than the education system, as likely factors influencing intergenerational economic mobility.
\end{abstract}

Jesse Rothstein

Goldman School of Public Policy and

Department of Economics

University of California, Berkeley

2607 Hearst Avenue \#7320

Berkeley, CA 94720-7320

and NBER

rothstein@berkeley.edu

A data appendix is available at http://www.nber.org/data-appendix/w24537 


\section{Introduction}

Chetty et al. (2014a, hereafter "CHKS") use data on the universe of U.S. tax filers to measure intergenerational income transmission - the strength of the association between parents' and children's incomes - at the fine geographic level, and reveal massive heterogeneity across space: The gap in adult earnings between children from high- vs. low-income families is nearly twice as large for children who grow up in Cincinnati as for those who grow up in Los Angeles. Little is known, however, about the mechanisms driving this variation.

There are many potential channels for intergenerational transmission, including differences in parenting practices between high- and low-income families, differences in explicit investments in children's education, differences in access to educational or other public institutions, and labor market institutions (such as insider hiring or spatial mismatch) that advantage children from high-income families regardless of their skills. These suggest quite different directions to look for potential policy interventions aimed at reducing transmission.

CHKS find that income transmission is negatively correlated with average test scores, high school completion, and school expenditures, and uncorrelated to average class size. This is suggestive, but these aggregate correlations are of limited value to understanding the mechanisms driving the variation across CZs. Income transmission is about differential outcomes of children from high- and low-income families, so to understand the mechanisms driving the between-area variation we need to understand how areas vary in the relative inputs received by and outcomes obtained by children from families with different incomes.

I investigate this directly, focusing on human capital accumulation as a potential mediator of intergenerational income transmission. If variation in school quality, or in parenting practices related to learning, is an important factor driving the variation in income transmission, we would expect that high income transmission areas would also be areas where the gap in educational outcomes between children from high- and low-income families is large. On the other hand, if parental income primarily helps children by, for example, buying them access to better labor market networks, then areas where poor children have good adult outcomes will not, in general, be areas where they do relatively well in school.

To measure children's educational outcomes, I rely primarily on the Education Longi- 
tudinal Survey (ELS). This is a representative national sample that includes information about parental income, children's achievement (test scores) near the end of high school, and educational attainment and early adult earnings and income. The ELS data can be geocoded to commuting zones $(\mathrm{CZs})$, the unit of geography considered by CHKS.

The ELS contains only about 15,000 respondents, far too few to produce reliable incomeachievement transmission measures for each of the $700 \mathrm{CZs}$ in the United States. I show that this is not necessary in order to accomplish the more limited goal of measuring the across-CZ association between income-income transmission and income-achievement transmission. That association is identified even with small numbers of observations from each $\mathrm{CZ}$ - information can be pooled from many $\mathrm{CZs}$ with similar income-income transmission to identify the average income-achievement transmission among them, even when the latter is not reliably estimated for any individual CZ. I develop an estimator for the slope of the CZ-level regression of intergenerational income transmission on income-achievement transmission, or for the correlation between the two, based on a mixed (random coefficients) model for the relationship between children's achievement and their parents' incomes.

I find that CZs vary substantially in the strength of transmission from parental income to children's 12th grade math scores (which I call "test score transmission"), but that this is only weakly correlated across CZs with income transmission. Income transmission is more strongly correlated to the strength of transmission from parental income to children's educational attainment, ${ }^{1}$ though the magnitude of the variation in the latter is not large enough to account for a large share of the former. These results suggest that differential inequities in access to good schools are not an important mechanism driving the across-CZ variation in income transmission; what role education does play seems to reflect access to higher education more than the quality of elementary and secondary schools.

This motivates me to consider other channels for intergenerational income transmission that may vary across CZs. One is the labor market return to skill. In every CZ, children from low-income families obtain less human capital than do children from higher income

\footnotetext{
${ }^{1}$ This reproduces a CHKS result for college enrollment, discussed below. Another similar result comes from Kearney and Levine (2016), who find that high school dropout gaps by family status are stronger in more unequal states (which tend to have stronger income transmission). Kearney and Levine (2014) find that non-marital childbearing is more common among low-SES women in these states as well.
} 
families. As a result, differences in the return to human capital could drive differences in income transmission even if the skill acquisition technology were the same everywhere. Indeed, I find that the return to education varies substantially across CZs, and explains as much of the variation in income transmission as do achievement and attainment gradients together. This points to labor market institutions as a potentially important factor.

I develop a decomposition that allows me to apportion the variation in CZ-level income transmission into four components: Accumulation of human capital, the earnings returns to human capital, the residual component of earnings that is explained by parental income conditional on the child's measured human capital, and non-earnings components of the child's family income (including spousal earnings and any non-labor income). I find that the final component, spousal and unearned income, accounts for two-fifths of the relative advantage of children from high-income families in high-transmission CZs. This reflects differences in the likelihood of marriage or in the age of marriage rather than assortative matching or inheritances. Another one-third operates through children's residual earnings. Skill accumulation and the return to skill each represents only one-ninth of the total.

My analysis is purely observational; my estimates of the association between CZ-level income transmission and CZ-level transmission of parental income to children's test scores and other outcomes could be confounded by other CZ-level characteristics that are correlated with both. Keeping this caveat in mind, my results indicate that human capital plays a relatively small role in the geographic variation in the intergenerational transmission of income. Much of this variation appears to reflect differences in adult earnings of children with similar skills, perhaps due to labor market institutions (e.g., unions, or other determinants of residual income inequality) or differences in access to good jobs (due, perhaps, to labor market networks or socially stratified labor markets). An even larger component is due to the use of family income-based (rather than individual earnings-based) measures of income transmission. This may be spurious, as differences in the likelihood of having spousal earnings, across income levels and across CZs, may simply reflect variation in age at marriage rather than true differences in opportunity across CZs, and may not be indicative of children's economic success.

My results on the mechanisms driving the existing variation in income transmission do 
not translate directly into policy implications. It may be possible to increase opportunity through educational interventions even though education is not a primary channel explaining differences in current opportunity. Nevertheless, my results suggest that the space of policies worthy of consideration should be broader than this. Policies related to labor market opportunity and outcomes may be more important, and merit at least as much attention.

\section{Data}

My analysis combines two sources of information: Measured income transmission at the CZ level, from CHKS's analysis of tax data, and survey data with information about parental income and children's human capital attainment. I discuss these in turn.

\subsection{Intergenerational income transmission}

CHKS discuss several ways of defining intergenerational mobility. I focus on what they call "relative mobility," the advantage that a child from a high-income family has, relative to a child from a low-income family in the same CZ, in achieving a high income as an adult. CHKS study children born between 1980 and 1982 and measure the income of child $i$ in CZ $c, y_{i c}$, as the average family income, including any spousal earnings and non-labor income, in 2011 and 2012, when the child is between 29 and 32. Children are linked to parents who claimed them as dependents in their late teens, and CHKS define $p_{i c}$ as the average parental family income - measured as the adjusted gross income plus tax-exempt interest and non-taxable Social Security benefits - for the parent(s) of child $i$ in 1996 through 2000. Both children's and parents' incomes are scaled as national percentile ranks in the relevant distributions, without adjustment for family size or the number of earners. Children are assigned to the CZ where their parents filed taxes in 1996, when the children were 14 to 16 years old.

CHKS define relative mobility in $\mathrm{CZ} c$ as the coefficient $\theta_{c}$ from a bivariate regression:

$$
y_{i c}=\alpha_{c}+p_{i c} \theta_{c}+e_{i c}
$$


Higher values of $\theta_{c}$ correspond to less mobility across generations, and I refer hereafter to $\theta_{c}$ as the strength of income transmission in the CZ. Universe tax data allows CHKS to estimate $\theta_{c}$ extremely precisely at the $\mathrm{CZ}$ level. They find that $\theta_{c}=0.43$ in Cincinnati, meaning that a one percentile difference in parental income is associated with a 0.43 percentile difference in children's eventual income, on average, in that city, and that in Los Angeles $\theta_{c}=0.23$, implying a relationship between parent and child income that is only a bit more than half as strong as in Cincinnati.

Table 1 presents unweighted summary statistics for $\theta_{c}$, extracted from CHKS's online data tables. The average of 0.33 indicates that in the average CZ, each one percentile increase in parental income is associated with one-third of a percentile increase in children's income. But the standard deviation of $\theta_{c}$ across CZs is 0.065. In $71 \mathrm{CZs}, \theta_{c}$ is less than 0.24 , indicating parent income-child income relationships about one-quarter weaker than the average, while another $78 \mathrm{CZs}$ have $\theta_{c}>0.40$, about one-quarter larger than average. Among the 100 largest CZs, Santa Barbara has the weakest income transmission, and Cincinnati the strongest.

\subsection{Survey data}

To measure the transmission of parental income to children's human capital accumulation, I use the Educational Longitudinal Study (ELS; Ingels et al., 2014a). This is a nationally representative, longitudinal sample of just over 19,000 10th graders in 2002, corresponding roughly to the 1985-1986 birth cohorts. Respondents were followed through 2012, when they were roughly 26. Math and reading scores are available in 10th grade, and math scores in 12th grade. I also construct children's adult income, $y_{i c}$, as their self-reported 2011 family income (including spousal earnings and non-labor income), when they were 25 or 26 years old. I assign students to CZs based on their residential zip codes in the base year survey, using information from subsequent surveys when this is missing.

I supplement the ELS with two similar panels. The Early Childhood Longitudinal Study, Kindergarten Cohort (ECLS-K; Tourangeau et al., 2009) sampled kindergarteners in 1998-9 and followed them through 8th grade in 2007. Students are assigned to CZs based on their 
8th grade residences. ${ }^{2}$ The High School Longitudinal Study (HSLS; Ingels et al., 2014b) provides high school test scores for children born in roughly 1994-1995. I assign them to the CZs they lived in during high school.

There are three major limitations of these samples for my purposes. Most importantly, sample sizes are well under 100 per CZ. Moreover, the surveys each use multi-stage sampling designs, with schools as one stage and then relatively large samples of students within each school. ${ }^{3}$ This means that within-CZ heterogeneity is even more limited than the small sample sizes imply. A consequence is that it is necessary to pool information across CZs in order to obtain any precision at all about the relationship between parental income and later outcomes (Gelman and Hill, 2006).

Second, none of the samples covers CHKS's 1980-82 birth cohorts. If income or test score transmission changed across cohorts, between-cohort comparisons may understate the relationship between the two. I explore sensitivity to this misalignment in two ways. First, I compare across the NCES samples, which differ in their distance from CHKS's cohorts. Results are quite similar, suggesting that between-cohort changes are not particularly important for my analysis. ${ }^{4}$ Second, the appendix presents results that use two alternative measures of income transmission, one from CHKS for the 1983-85 birth cohorts - very close to the ELS cohorts - and one from Chetty and Hendren's (forthcoming) mobility-based estimate based on children born between 1980 and 1991. None of the results presented here differ meaningfully when either alternative is used.

A final important limitation is that, while all three studies included parental surveys, the parental income measures are extremely limited. The ELS collects only total family income, and only in the base year. The measure is categorical, with 13 bins (e.g., one corresponds to incomes between $\$ 25,000$ and $\$ 35,000$ ). The HSLS collected family income twice, and reports it continuously. The ECLS data include a continuous measure in Kindergarten and

\footnotetext{
${ }^{2}$ Where 8 th grade residences are unavailable, I use the location of the 8th grade school, then the 5th grade residence and school, then 3 rd grade, and so on.

${ }^{3}$ The regressions below account for CZ-level (or within-CZ) clustering, but do not otherwise adjust for the survey designs. Most of my estimates are unweighted, but results are generally robust to using student-level sampling weights when specifications permit it.

${ }^{4}$ Chetty et al. (2014b) find that national aggregate relative mobility has been quite stable across a range of birth cohorts (born 1971-1993), but CZ-level measures might in principle vary across cohorts with little variation in the national aggregate. See also Aaronson and Mazumder (2008).
} 


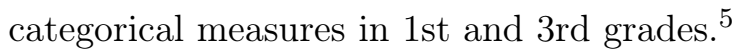

I also present an analysis of returns to education in American Community Survey (ACS) data. For maximum comparability with CHKS's measures, I use the 2010, 2011, and 2012 one-year public use microdata samples, and focus on the 253,852 individuals in these samples born between 1980 and 1982. I convert annual family incomes to percentiles within the ACS sample distribution. I do not have information about where respondents lived as children, so I assign them to the $\mathrm{CZ}$ where they live at the time of the survey.

Summary statistics for the four microdata samples are reported in Table $2 .{ }^{6}$ Following CHKS, my primary analysis converts incomes, earnings, and test scores to percentiles within the relevant samples; these have mean 50.0 and standard deviation 28.9 by construction. For parental income, I assign ELS categories to the midpoints of the national percentile range they span; in the HSLS and ECLS, I average incomes across the available waves, using bin midpoints as necessary, and construct percentiles of the distribution of averages. There is surely non-classical measurement error in each of the measures when scaled as percentiles. ${ }^{7}$ There is no reason to expect the resulting bias to differ across CZs or across dependent variables, however. Appendix Figure A1 shows that percentile-percentile relationships between parental income and various children's outcomes are roughly linear in the ELS sample. Appendix Table A7 presents results that use alternative scales for parental income and child test scores.

Table 2 shows that $84 \%$ of ELS respondents report ever having attended a postsecondary educational institution by the age- 26 survey. This is much higher than the $53 \%$ reporting some college or more in the ACS sample. In CHKS's tax data, $60 \%$ of children are recorded as attending college between 18 and 21. Only half of the college attenders in the ELS sample

\footnotetext{
${ }^{5}$ I can assess the reliability of individual binned measures by comparing the same family's income across the three ECLS waves. As discussed below, I scale incomes as percentiles of the sample distribution. Percentiles constructed from the 1st and 3rd grade wave bin midpoints are correlated 0.84; the Kindergarten percentile is correlated 0.86 and 0.80 with the 1 st and 3rd grade measures, respectively. A percentile constructed from the average of the three is correlated 0.94-0.95 with the individual measures.

${ }^{6}$ Mean parental incomes vary across samples. This in part reflects inflation (I report nominal values) and life cycle considerations (ECLS parents are on average younger when their incomes are collected than ELS or HSLS parents).

${ }^{7}$ The ELS test scores - in math and reading in 10th grade, and in math in 12 th grade - are point estimates of student proficiency from an Item Response Theory (IRT) model. Measurement error does not bias student performance on the original IRT scale, but will tend to compress gaps between groups on the percentile scale (Jacob and Rothstein, 2016). This likely attenuates my estimates of income-to-achievement transmission, but should not bias the between-CZ comparisons that are my primary interest.
} 
earned a college degree; in the ACS, the share without a degree is under $30 \%$. It appears that the ELS is counting some respondents with weak postsecondary attachment as having attended college who would not be so counted in other data sets. I discuss this further below.

\section{Conceptual framework and empirical strategy}

Subsection 3.1 lays out a simple model in which human capital mediates the relationship between parent and child income. Subsection 3.2 develops a methodology for estimating the key elements of the model - and in particular how they vary across CZs - with the limited available data. Subsection 3.3 describes a decomposition of the across-CZ variation in income transmission into various component mechanisms.

\subsection{Children's human capital as a mediator of intergenerational income transmission}

Let $s_{i c}$ be a potential mediator of the relationship between parental income $p_{i c}$ and children's income $y_{i c}$, such as the child's educational attainment or achievement. Its importance as a mediator depends on the strength of its relationship to $p_{i c}$, and on the extent to which it accounts to the relationship between $p_{i c}$ and $y_{i c}$. Assuming linear and additive relationships, we have a simple system:

$$
s_{i c}=\alpha+p_{i c} \pi+u_{i c}
$$

and

$$
y_{i c}=\kappa+s_{i c} \lambda+p_{i c} \mu+v_{i c} \text {. }
$$

These equations represent reduced-form transmission and are statistical projections, not causal models. The system is illustrated in Figure 1. The coefficient $\pi$ represents the importance of parental income as a determinant of $s_{i c}$. $\lambda$ is the return to $s_{i c}$ in children's incomes, while $\mu$ is the "direct" effect of parental income on children's income, not mediated by $s_{i c}$. 
Plugging (2) into (3) and rearranging, we obtain:

$$
y_{i c}=(\kappa+\alpha \lambda)+p_{i c}(\pi \lambda+\mu)+\left(u_{i c} \lambda+v_{i c}\right) .
$$

Thus, the reduced-form transmission of parental income to child's income studied by CHKS is, in this framework, the sum of a component operating through the potential mediator and the direct effect:

$$
\theta \equiv \pi \lambda+\mu
$$

Each of the coefficients in (2) and (3) may vary across CZs, and all may depend in important ways on local institutions and policies. For example, when $s_{i c}$ is a human capital measure, a CZ with a bad system of public education, in which only those who can afford private school tuition (or, perhaps, a house in one of the few excellent public school districts) can obtain good schools for their children, would have a high $\pi$. A very unequal CZ labor market, with high wages for those with high human capital but few opportunities for those with little, would yield a high $\lambda$. Finally, a labor market in which strong family networks are needed to access good job opportunities would imply high $\mu$. Thus, understanding which of these accounts - even descriptively - for the between-CZ variation in $\theta$ would inform further investigation of the determinants of intergenerational transmission.

\subsection{Estimating the importance of test score transmission as a mediator using across- $\mathrm{CZ}$ variation}

A barrier to estimating equations (2) and (3) is that few data sets contain all of the necessary measures. Tax data provide $p_{i c}$ and $y_{i c}$ for enormous samples, but only one potential mediator, whether the child enrolls in college by age 21. Using this as $s_{i c}$, CHKS estimate $\pi_{c}$ for each $\mathrm{CZ}$ and find that it is highly correlated with $\theta_{c}(\rho=0.68)$. However, as I discuss below, for plausible $\lambda$ the variation in $\pi_{c}$ is too small to account for more than a small share of the variation in $\theta_{c}$.

The ELS provides richer measures of human capital, but for a sample that is far too small to permit reliable estimation of $\pi_{c}$ for each CZ. In lieu of this, I develop a methodology for 
estimating the across-CZ bivariate regression of $\theta_{c}$ on $\pi_{c}$, even when CZ-level samples are too small to permit estimation of $\pi_{c}$ directly. ${ }^{8}$ The slope of this regression can be interpreted as an (observational) estimate of $\lambda$. The $R^{2}$ provides an initial estimate of the share of the variance of $\theta_{c}$ that is attributable to the mediating role of human capital accumulation. In subsection 3.3, I develop a more careful decomposition.

My approach is built from the "reverse" projection of $\pi_{c}$ onto $\theta_{c}$ :

$$
\pi_{c}=\gamma+\theta_{c} \beta+\eta_{c}
$$

where $\beta=\operatorname{cov}\left(\theta_{c}, \pi_{c}\right) / \sigma_{\theta}^{2}$ is the across-CZ linear projection coefficient and $\eta_{c}$ is orthogonal to $\theta_{c}$ by construction. If the terms of (6), including the residual variance $\sigma_{\eta}^{2}$, were known it would be straightforward to obtain the forward regression of $\theta_{c}$ on $\pi_{c}$,

$$
\frac{\operatorname{cov}\left(\theta_{c}, \pi_{c}\right)}{\sigma_{\pi}^{2}}=\frac{\operatorname{cov}\left(\theta_{c}, \pi_{c}\right)}{\sigma_{\theta}^{2}} \frac{\sigma_{\theta}^{2}}{\sigma_{\pi}^{2}}=\beta \frac{\sigma_{\theta}^{2}}{\sigma_{\theta}^{2} \beta^{2}+\sigma_{\eta}^{2}}
$$

the $R^{2}$ (which is the same for the forward and reverse regressions),

$$
R^{2}=\beta^{2} \frac{\sigma_{\theta}^{2}}{\sigma_{\pi}^{2}}=\beta^{2} \frac{\sigma_{\theta}^{2}}{\sigma_{\theta}^{2} \beta^{2}+\sigma_{\eta}^{2}}
$$

and the correlation between $\theta_{c}$ and $\pi_{c}, \operatorname{corr}\left(\theta_{c}, \pi_{c}\right)=\sqrt{R^{2}}$. Note that $\theta_{c}$ and therefore $\sigma_{\theta}^{2}$ are observed directly, in CHKS's computations from population data.

To estimate (6), I return to equation (2), making explicit the variation in the coefficients across CZs:

$$
s_{i c}=\alpha_{c}+p_{i c} \pi_{c}+u_{i c}
$$

Substituting (6) into (9), we obtain

$$
s_{i c}=\alpha_{c}+p_{i c}\left(\gamma+\theta_{c} \beta+\eta_{c}\right)+u_{i c}
$$

\footnotetext{
${ }^{8} \mathrm{I}$ model $s_{i c}$ as a mediator of $y_{i c}$, and thus $\pi_{c}$ as a mediator of $\theta_{c}$. However, reverse causality from income transmission, $\theta_{c}$, to human capital transmission, $\pi_{c}$, is possible. For example, it may be easier to attract high-ability college graduates into teaching in $\mathrm{CZs}$ with more equal labor markets, creating a causal path from economic mobility to gaps in children's outcomes.
} 
Equation (10) is the basis of my analysis. It leads to four types of specifications. First, a simple national regression of $s_{i c}$ on $p_{i c}$ restricts $\beta=0$ and $\sigma_{\eta}^{2}=0$.

Second, I divide the nation into deciles of the distribution of $\theta_{c}$ and regress $s_{i c}$ on $p_{i c}$ separately in each decile $d$. By regressing the coefficients $\hat{\gamma}_{d}$ from these regressions on average income transmission in each decile, $\bar{\theta}_{d}$, I can test whether $\beta=0 .{ }^{9}$

Third, returning to pooled data, I can add to the national regression an interaction of $p_{i c}$ with $\theta_{c}$. This interaction coefficient estimates $\beta$ in one step:

$$
s_{i c}=\alpha_{c}+p_{i c} \gamma+\left(p_{i c} \theta_{c}\right) \beta+e_{i c} .
$$

The error term here is $e_{i c} \equiv p_{i c} \eta_{c}+u_{i c}$; because both (9) and (6) are linear projections, it is orthogonal to $p_{i c}$ and $p_{i c} \theta_{c}$ by construction. To ensure that $\gamma$ and $\beta$ are identified from within-CZ variation, I divide $p_{i c}$ into its between- and within-CZ components, and include main effects and $\theta_{c}$ interactions for each. I also remove the grand mean of $\theta_{c}$ to permit comparisons of $\gamma$ to the simpler specification, and include a main effect for $\left(\theta_{c}-\bar{\theta}\right)$. Defining $\tilde{p}_{i c} \equiv p_{i c}-\bar{p}_{c}$, and $\tilde{\theta}_{c} \equiv \theta_{c}-\bar{\theta}$, the regression is:

$$
s_{i c}=\alpha_{c}+\tilde{p}_{i c} \gamma+\tilde{p}_{i c} \tilde{\theta}_{c} \beta+X_{c} \Omega+e_{i c}
$$

where $X_{c}$ includes $\bar{p}_{c}, \bar{p}_{c}\left(\theta_{c}-\bar{\theta}\right)$, and $\left(\theta_{c}-\bar{\theta}\right)$. This is equivalent to simply controlling for $X_{c}$ in (10). I explore OLS, (correlated) random effects, and fixed effects specifications for $\alpha_{c}$, in each case reporting standard errors that are clustered at the CZ level to handle the dependence of $e_{i c}$.

Finally, my primary estimates are based on the full model (10), without restrictions. It can be seen as a random coefficients model, also known as a mixed model, with fixed coefficients $\gamma$ and $\beta$ and random coefficients $\alpha_{c}$ and $\eta_{c}$. If we assume that $\left(\alpha_{c}, \eta_{c}\right)$ and $u_{i c}$ are each normally distributed and i.i.d., it can be estimated by maximum likelihood. ${ }^{10}$ This

\footnotetext{
${ }^{9}$ With more data, one could use smaller cells. In the limit, with the first-stage regression estimated in each CZ separately, it estimates $\pi_{c}$, and the second-stage regression of $\hat{\pi}_{c}$ on $\theta_{c}$ is equation (6) and estimates $\beta$. I present this analysis in the appendix, but it is poorly behaved in the small ELS sample.

${ }^{10}$ Gelman and Hill (2006) discuss the estimation of models like (10), which are referred to variously as mixed, hierarchical, random coefficient, or multi-level models. There is no fully satisfactory way to handle sampling weights in these models. Accordingly, I estimate them without weights. In simpler models,
} 
yields an estimate not just of $\beta$ but also of $\sigma_{\eta}^{2}$, so can be used to compute the forward regression (7). As in the fixed-coefficient specification, I separate $\bar{p}_{c}$ from $p_{i c}-\bar{p}_{c}$, to ensure that only within-CZ variation identifies the coefficients of interest. ${ }^{11}$ The identifying assumption (beyond normality) is that $\eta_{c}$ is orthogonal to $\theta_{c}$. Recalling that $\eta_{c}$ is the residual in (6), this simply means that the mixed model identifies only the observational regression of $\pi_{c}$ on $\theta_{c}$ (and vice versa), and does not solve the causal inference problem.

One way to validate this strategy is to use the child's income as the skill measure - that is, let $s_{i c} \equiv y_{i c}$. This makes transmission to skill, $\pi_{c}$, identical to transmission to child's income, $\theta_{c}$, thus ensuring that $\beta=1$ and $\sigma_{\eta}^{2}=0$ in (6). I implement a version of this in Appendix Table A2. Results are encouraging, though not perfect. The estimate of $\sigma_{\eta}^{2}$ is nearly identically zero - a result that does not occur for any of the other outcomes I examine below. The estimated $\beta$ coefficient, however, is attenuated by about one-third from what was expected. I attribute this to the fact that this exercise mixes two different data sets $\theta_{c}$ is measured in tax data, while I measure $y_{i c}$ and $p_{i c}$ in the ELS. As discussed above, the ELS measure of $p_{i c}$ is of lower quality than the tax measure, while the ELS $y_{i c}$ is measured at a younger age.

A different mixed model can be used to estimate the relationship between $\theta_{c}$ and the return to skill in the local labor market, defined as the coefficient of a regression of incomes on human capital:

$$
y_{i c}=\tilde{\kappa}_{c}+s_{i c} \tilde{\lambda}_{c}+\tilde{v}_{i c}
$$

The standard omitted variables formula can be used to relate this reduced-form coefficient to the transmission coefficients from the path diagram in Figure 1:

$$
\tilde{\lambda}_{c}=\lambda_{c}+\frac{\operatorname{cov}\left(s_{i c}, p_{i c}\right)}{V\left(s_{i c}\right)} \mu_{c}=\lambda_{c}+\frac{\sigma_{p}^{2}}{\sigma_{s}^{2}} \pi_{c} \mu_{c}
$$

estimates are very similar with and without weights, so this is not likely to dramatically affect my results. In economics, it is common to estimate models like (10) in two stages, as in footnote 9 . This does not require a normality assumption on $\left(\alpha_{c}, \eta_{c}\right)$, but estimation of $\sigma_{\eta}^{2}$ requires distinguishing what portion of the across-CZ variation in $\hat{\pi}_{c}$ is due to sampling error. As noted above, this is poorly behaved in the ELS sample. The mixed model approach can achieve better precision by pooling information across CZs.

${ }^{11}$ The random coefficient is specified to apply only to $p_{i c}-\bar{p}_{c}$, so the random intercept is $\tilde{\alpha}_{c}=\alpha_{c}+\bar{p}_{c} \eta_{c}$. I do not restrict the correlation between $\tilde{\alpha}_{c}$ and $\eta_{c}$. In most specifications, the estimated correlation is quite close to 1 , suggesting that $\sigma_{\alpha}^{2}$ is small. 
As above, my starting point is the hypothetical reverse regression of $\tilde{\lambda}_{c}$ on $\theta_{c}: \tilde{\lambda}_{c}=\gamma^{\tilde{\lambda}}+$ $\theta_{c} \beta^{\tilde{\lambda}}+\eta_{c}^{\tilde{\lambda}}$. Substituting this into (13) yields a mixed model similar to (10):

$$
y_{i c}=\tilde{\kappa}_{c}+s_{i c}\left(\gamma^{\tilde{\lambda}}+\theta_{c} \beta^{\tilde{\lambda}}+\eta_{c}^{\tilde{\lambda}}\right)+\tilde{v}_{i c} .
$$

The parameters of this model can again be used to compute the regression of $\theta_{c}$ on $\tilde{\lambda}_{c}{ }^{12}$

\subsection{Decomposing the across- $\mathrm{CZ}$ variation in income transmission}

The mixed models yield separate estimates of the relationships between $\theta_{c}$ and $\pi_{c}$ and between $\theta_{c}$ and $\tilde{\lambda}_{c}$. Also of interest is the decomposition of the across-CZ variation in $\theta_{c}$ into its component parts. In this subsection I outline a strategy to decompose the separate contributions of variation in $\pi_{c}, \lambda_{c}$, and $\mu_{c}$.

My starting point is the "structural" equation (3), allowing for CZ-level heterogeneity in the coefficients:

$$
y_{i c}=\kappa_{c}+s_{i c} \lambda_{c}+p_{i c} \mu_{c}+v_{i c} .
$$

The gradient of this with respect to parent income in $\mathrm{CZ} c$ is:

$$
\left.\frac{d y_{i c}}{d p_{i c}}\right|_{c}=\left.\frac{d s_{i c}}{d p_{i c}}\right|_{c} \lambda_{c}+\mu_{c}
$$

Given the definitions of $\theta_{c}$ and $\pi_{c}$, this is simply the decomposition defined earlier:

$$
\theta_{c}=\pi_{c} \lambda_{c}+\mu_{c}
$$

The across-CZ gradient of (17) with respect to $\theta_{c}$ is:

$$
\frac{d^{2} y_{i c}}{d p_{i c} d \theta_{c}}=\frac{d^{2} s_{i c}}{d p_{i c} d \theta_{c}} \lambda_{c}+\left.\frac{d s_{i c}}{d p_{i c}}\right|_{c} \frac{d \lambda_{c}}{d \theta_{c}}+\frac{d \mu_{c}}{d \theta_{c}}
$$

\footnotetext{
${ }^{12}$ In principle, one could estimate the relationships of $\theta_{c}$ with $\lambda_{c}$ and $\mu_{c}$ via a version of this strategy, by including a control for $p_{i c}$ in (13), with its own fixed and random coefficients. I have explored this model, but it is quite poorly behaved. I do use a fixed-coefficient version of this model in the decomposition discussed in subsection 3.3.
} 
or, using (18),

$$
1=\frac{d \pi_{c}}{d \theta_{c}} \lambda_{c}+\pi_{c} \frac{d \lambda_{c}}{d \theta_{c}}+\frac{d \mu_{c}}{d \theta_{c}}
$$

Each of the terms on the right side of (20) is interpretable as reflecting a distinct component of income transmission. The first term represents differences between high- and low- $\theta_{c} \mathrm{CZs}$ in human capital accumulation gaps between high- and low-income families, scaled by the return to human capital. But for scaling by $\lambda_{c}$, this term is identified by the $\beta$ coefficient of the "reverse" regression (6) discussed above in subsection 3.2. It would be large if high- $\theta_{c}$ CZs offer less equal school quality to children from different family backgrounds.

The second term reflects covariance of the CZ-level return to skill with CZ-level income transmission, scaled by $\left.\pi_{c} \equiv \frac{d s_{i c}}{d p_{i c}}\right|_{c}$. This term would be large if high- $\theta_{c}$ CZs have higher returns to skill, producing better outcomes for children from high-income families who tend to obtain higher skill. The third term reflects differences in the transmission of parental income to children's incomes holding skills constant. This might be large if high- $\theta_{c} \mathrm{CZs}$ have segmented labor markets or employment networks that allow high-income parents to ensure good outcomes for their children regardless of the children's skills.

To decompose the variation across cities, I use fixed values $\bar{\lambda}$ and $\bar{\pi}$ to scale the first and second terms:

$$
\begin{aligned}
\frac{d^{2} y_{i c}}{d p_{i c} d \theta_{c}} & =\frac{d^{2} s_{i c}}{d p_{i c} d \theta_{c}} \lambda_{c}+\pi_{c} \frac{d \lambda_{c}}{d \theta_{c}}+\frac{d \mu_{c}}{d \theta_{c}} \\
& \approx \frac{d^{2} s_{i c}}{d p_{i c} d \theta_{c}} \bar{\lambda}+\bar{\pi} \frac{d \lambda_{c}}{d \theta_{c}}+\frac{d \mu_{c}}{d \theta_{c}}
\end{aligned}
$$

This leads to a three-step method for the decomposition. First, I estimate $\bar{\lambda}$ and $\bar{\pi}$ via pooled regressions of $y_{i c}$ on $s_{i c}$ and of $s_{i c}$ on $p_{i c}$, respectively. Second, I estimate $\frac{d^{2} s_{i c}}{d p_{i c} d \theta_{c}}=\frac{d \pi_{c}}{d \theta_{c}}=\beta$ via a regression of $s_{i c}$ on $p_{i c}, \theta_{c}$, and their interaction as in (11), above. Third, I regress $y_{i c}$ on $s_{i c}, p_{i c}, \theta_{c}$, and the two interactions $s_{i c} * \theta_{c}$ and $p_{i c} * \theta_{c}$. The interaction coefficients estimate $\frac{d \lambda_{c}}{d \theta_{c}}$ and $\frac{d \mu_{c}}{d \theta_{c}}$, respectively. As earlier, I include in each step the CZ means of the individual-level variables, as well as CZ random effects.

Next, consider the left side of (22). In principle, $\left.\frac{d y_{i c}}{d p_{i c}}\right|_{c}$ is identically equal to $\theta_{c}$, and 
its derivative with respect to $\theta_{c}$ is therefore 1 . In practice, I rely on CHKS's estimates of $\theta_{c}$ from tax data and measures of $y_{i c}$ and $p_{i c}$ from the ELS. In this blended data set, the regression of $y_{i c}$ on $p_{i c}, \theta_{c}$, and $p_{i c} \theta_{c}$ has an interaction coefficient well below one. This reflects measurement differences between the ELS sample and the tax data. I take the empirical interaction coefficient as the target of my decomposition.

A final issue is that CHKS define $y_{i c}$ as family income, including any spousal earnings and non-labor income. There are thus two channels for each of the elements of the decomposition. The return to human capital in the second term, for example, includes both labor market and spousal market returns. These point to different structural factors of the CZ as explanations. Moreover, spousal market components of transmission may be artifacts of the fact that I measure children's income at a single point in time, when children are around 25: CZs where children from high-income families typically marry young will have higher measured income transmission than do CZs where these children typically marry later, but may not meaningfully differ in the extent of available opportunity. Therefore, I separate children's incomes into their own earnings $w_{i c}$ and the remaining component, reflecting spousal earnings and non-labor income: $y_{i c}=w_{i c}+\left(y_{i c}-w_{i c}\right)$. I apply the above decomposition only to the children's earnings, and consider the reduced-form transmission of parental income to children's spousal and non-labor income as a separate mechanism.

\section{Results}

I present results in four parts. First, to lay the groundwork, I present national estimates of the path diagram in Figure 1, using the ELS sample. Second, I use the variation in these estimates across CZs to identify the relationship between income transmission $\theta_{c}$ and human capital transmission $\pi_{c}$. Third, I use ELS and ACS data to examine variation in the reducedform return to skill $\tilde{\lambda}_{c}$ across CZs, again relating it to CZ-level income transmission. Finally, I implement the decomposition described in subsection 3.3, attributing variation across CZs in income transmission to marriage market factors, skill accumulation, returns to skill, and direct transmission of parental income to children's earnings. 


\subsection{National estimates}

Table 3 presents estimates of the national relationships between parental income, children's human capital, and children's incomes, using the ELS sample. All specifications are weighted and include CZ fixed effects.

Columns 1 and 2 show the reduced-form relationships between parental income and children's 12th grade math scores and educational attainment, respectively. Each percentile of parental income is associated with 0.35 percentiles of children's achievement, and with 0.019 years of education. ${ }^{13}$ Column 3 presents an analysis of reduced-form income transmission. Each percentile of parental income is associated with 0.16 percentiles of children's adult incomes.

Columns 4-6 show regressions of the child's adult family income on the two human capital measures, first separately and then together. Each math score percentile is associated with 0.24 percentiles in additional income, while each year of education is associated with 3.6 percentiles. Each coefficient falls, as expected, when both measures are included together. Finally, column 7 includes both parental income and child human capital controls. Here, the parental income coefficient represents $\mu$ in the path diagram. This is 0.07 , less than half of what it was without human capital controls in Column 3, but nevertheless highly significant. The test score and education coefficients, representing $\lambda$, are only slightly reduced from column 6 . The role of human capital as a mediating factor can be computed by multiplying these coefficients by the corresponding $\pi$ coefficients in columns 1 and 2 . This yields $0.35 *$ $0.18+0.019 * 1.76=0.098$, or roughly $60 \%$ of the total transmission in column 3 .

The national analysis thus indicates that human capital is an important mediating factor in intergenerational income transmission. As we will see, human capital plays a much smaller role in explaining the across- $\mathrm{CZ}$ variation.

\footnotetext{
${ }^{13}$ Bradbury et al. (2015) find that the parental income coefficient is largely invariant to the age at which children's test scores are measured. I look across a larger range and find that it grows somewhat with age see Appendix Table A1. Bradbury et al. (2015) also compare results across four English-speaking countries. This exercise is similar in spirit to my comparison across commuting zones.
} 


\subsection{Transmission from parental income to children's human capital across $\mathrm{CZs}$}

In this subsection, I examine variation across CZs in the transmission of parental income to children's human capital. I examine test scores first, then educational attainment.

\subsubsection{2th grade math scores in the ELS}

As a first effort to explore across-CZ variation, I divide $\mathrm{CZs}$ into ten deciles based on $\theta_{c}$. For each decile, I estimate a separate regression of children's test scores on parental income, with CZ fixed effects. Figure 2 plots the parental income coefficients and confidence intervals against the mean of $\theta_{c}$ in the decile. The slope of the best-fit line to this scatterplot, which corresponds to $\beta$ in (10), is 0.25 , indicating that parental income is more strongly associated with children's test scores in high income transmission than in low income transmission CZs. The implied difference between the 3rd and the 8th deciles - corresponding roughly to the interquartile range of $\theta_{c}$ - is a 0.021 increase in the slope shown in column 1 of Table 3. However, the figure also indicates substantial variation around the best-fit line, likely more than could be explained by sampling error.

Table 4 presents parametric estimates of the interacted specifications (11) and (10). I begin with a specification that does not allow for a $\theta_{c}$ interaction, as in Table 3 , but show both within- and between-CZ coefficients. ${ }^{14}$

Columns 2-4 include interactions between parental income and CZ income transmission $\theta_{c}$. Column 2 is an OLS specification without CZ-level variation in the intercept (but with a $\theta_{c}$ main effect); column 3 is a Generalized Least Squares model with CZ random effects; and column 4 includes CZ fixed effects. The interaction coefficient from each specification estimates the coefficient $\beta$ in (11); it measures the extent to which CZs with strong transmission from parent income to child income also exhibit strong transmission from parent income to children's test scores. This coefficient is 0.32 in the OLS and FE specifications

\footnotetext{
${ }^{14}$ The ELS is a multi-stage sample in which schools are sampled and students are sampled within schools. When I decompose $p_{i c}-\bar{p}_{c}$ into the deviation from the school mean and the difference between school and CZ means, the across-CZ and within-CZ, across-school coefficients are indistinguishable, and the within-school coefficient is much smaller. This is exactly what one would expect based on measurement error in $p_{i c}$, but could also derive from sorting into schools based on unobservables or school-based peer effects.
} 
and 0.37 in the RE specification; the difference reflects the use of sampling weights in the OLS and FE specifications but not in the RE specification. Each is a fair amount larger than the 0.25 estimate of $\beta$ from Figure 2 and is comparable in magnitude to the within-CZ parental income main effect. While income-achievement transmission is (in column 3) 0.34 in the average $\mathrm{CZ}$, it is 0.32 in a $\mathrm{CZ}$ at the 25 th percentile of the $\theta_{c}$ distribution and 0.36 in a $\mathrm{CZ}$ at the 75 th percentile. As in Figure 2, these estimates are consistent with test scores being a meaningful, though not overwhelming, mediator of the between-CZ difference in the transmission of income across generations.

Column 5 presents the mixed model (10), allowing $\sigma_{\eta}^{2}>0$. This allows for variation across CZs in income-achievement transmission that is not predicted by the CZ's incomeincome transmission. I estimate $\sigma_{\eta}=0.07$. The hypothesis that $\sigma_{\eta}^{2}=0$ is decisively rejected. ${ }^{15}$ The lower portion of the table shows various summaries of the joint distribution of $\theta_{c}$ and $\pi_{c}$ that is implied by the mixed model coefficients. The standard deviation of $\pi_{c}$ is 0.072 , much larger than in previous columns. A CZ at the 25th percentile of the $\pi_{c}$ distribution has income-test score transmission coefficient 0.28 , while one at the 75 th percentile has coefficient 0.38 . Most of this variation comes from the $\eta_{c}$ component that is orthogonal to $\theta_{c}$, however: The correlation between $\theta_{c}$ and $\pi_{c}$ is only 0.32 .

The slope of $\theta_{c}$ with respect to $\pi_{c}$ is a statistically significant 0.26 (S.E. 0.12): On average, in CZs in which the test score advantage of children from rich families is 1 percentile larger than average, the adult income advantage is about 0.26 percentiles larger than in the average CZ. This is relatively small, but consistent with the national evidence. Table 3, column 1 indicates that students whose test scores are one percentile above average tend to have adult incomes 0.24 percentiles above average. Here, we find that $\mathrm{CZs}$ where the test score gap between high-income and low-income students is one percentile greater than in the average $\mathrm{CZ}$ have adult income gaps between those students that are, on average, 0.26 percentiles larger than in the average $\mathrm{CZ}$. These are strikingly similar, and appear to point to a meaningful role for student achievement as a mediator of income transmission.

\footnotetext{
${ }^{15}$ The null hypothesis that $\sigma_{\eta}=0$ is on the boundary of the parameter space for the mixed model likelihood function. The test is a likelihood ratio test based on the comparison of column 5 to the specification in column 3, estimating the latter by maximum likelihood rather than by GLS. Note that the null hypothesis that $\sigma_{\eta}^{2}=0$ corresponds to a perfect correlation between $\theta_{c}$ and $\pi_{c}$, and to an $R^{2}$ of 1 in the regression of the former on the latter.
} 
However, it is worth considering the magnitude of the across-CZ variation in test score transmission. I estimate that the standard deviation of $\pi_{c}$ is 0.072 . Take 0.24 as the return to a one percentile increase in test scores. Thus, each standard deviation of $\pi_{c}$ drives an increase of $\theta_{c}$ of $0.072 * 0.24=0.018$. But the standard deviation of $\theta_{c}$ is 0.057 , over three times as large. In other words, there is much more variability in $\mathrm{CZ}$ income-income transmission than can be operating through the test score channel: Only $11 \%$ of the across$\mathrm{CZ}$ variation in the former is explained by the latter. There are evidently other channels that account for the bulk of the geographic variation in income transmission; test scores, and the knowledge and skills that they represent, are a mechanism, but not the dominant one.

\subsubsection{Test scores across grades and subjects}

By estimating the models in Table 4 for test scores measured at different ages, I can explore whether the relative advantage of high-income children in high-transmission CZs appears to grow with age, as might be expected if schools play a role in income transmission. This analysis is likely sensitive to scaling decisions (Bond and Lang, 2013, forthcoming). I scale scores at each age in national percentiles, but a one percentile advantage in kindergarten may not mean the same thing as a one percentile advantage in 12th grade. Setting this issue aside, Table 5 presents mixed model estimates for each of the available test scores from the ECLS, ELS, and HSLS. The $\beta$ coefficients in column 2 are similar in magnitude across most of the specifications, though imprecisely estimated. The random component of the parental income coefficient $\left(\sigma_{\eta}\right.$, in column 3$)$ is meaningful in each row, and column 6 indicates that the null hypothesis that $\sigma_{\eta}=0$ is rejected in all but one case. The slope of $\theta_{c}$ with respect to $\pi_{c}$ (column 4) is modest and generally larger for reading than for math. It appears to grow somewhat with age, though this is not entirely consistent. Correlations between $\theta_{c}$ and $\pi_{c}$ (column 5) are quite low across grades and subjects, but again larger in later grades.

The pattern of results has several implications. First, there is some indication that the relative importance of parental income to student test scores in high-income-transmission CZs grows between kindergarten and high school, consistent with the hypothesis that differential access to school quality (rather than, say, parenting practices) is a mechanism 
contributing to differential income transmission. Second, there is substantial heterogeneity across CZs in the transmission of parental income to children's test scores that is not associated with CZ-level income transmission, indicating that the institutions or other CZ characteristics that contribute to test score transmission differ from those determining income transmission. Put somewhat differently, there is only a modest correlation across CZs between income-income and income-test score transmission, even in later grades, so different influences must be at work. Finally, results are quite similar for the HSLS as for the ELS, though the latter is much closer to the cohorts for which $\theta_{c}$ is computed, suggesting that cohort differences are unable to explain the weak relationship of income-income and income-test score transmission in the HSLS and ECLS.

\subsubsection{Educational attainment}

I have thus far used test scores as a summary of children's human capital. An alternative is to focus on educational attainment. I consider two summaries of attainment as of the last ELS survey, around age 26: an indicator for a four-year degree and the number of years of education. As discussed above, the ELS counts a surprisingly large share of students as having attended some college, and results for this outcome (presented in the appendix) are highly discrepant, and appear to be driven by over-measurement of college attendance in the ELS. The other two attainment summaries are closer to expectations (Table 2).

Columns 1 and 3 of Table 6 present estimates of the interacted specification (11), with CZ random effects, for the two measures. (I report only the coefficients pertaining to within-CZ variation in parental income, though CZ means and an income transmission main effect are included as before.) Not surprisingly, parental income is strongly related to both measures of children's attainment. The interaction coefficient $\beta$ is large and statistically significant for each outcome.

Columns 2 and 4 present the mixed model specifications. Likelihood ratio tests do not reject the restrictions that the parental income random coefficients are zero (i.e., $\sigma_{\eta}=$ $0)$. Coefficients of regressions of income transmission on income-attainment transmission yield modest coefficients: CZs where students from high-income families are 1 percentage point more likely to graduate from college (relative to students from low-income families) 
have adult income gaps between children from high- and low-income families that are 0.32 percentiles larger, and CZs where the high-income children earn one more year of education have adult income gaps that are 12 percentiles larger. Neither of these is significantly different from zero.

The correlation between income transmission and attainment transmission is stronger than for test scores, around 0.5. However, this is still quite far from 1; three-quarters of the variance in income transmission across CZs is unexplained by differences in transmission from parental income to children's higher education attainment. As in the earlier analysis of test scores, the evidence points to a role for educational attainment as a mechanism driving variation in intergenerational income transmission, but does not indicate that it is an overwhelming factor.

The $R^{2}$ statistics in the lower portion of Table 6 provide one way to measure the importance of the attainment channel. Variation across CZs in the transmission of parental income to educational attainment in years explains about one-quarter of the variability in CZ-level income transmission. As with test scores, another way to understand this is to use an estimate of the return to education to measure the importance of educational attainment as a mediator of income transmission. I begin with CHKS's measure of transmission from parental income to college enrollment. They find that the standard deviation of $\pi_{c}$, across $\mathrm{CZs}$, is 0.11 percentage point of college enrollment per percentile of family income, very similar to my estimate in column 2 of Table 6 . In a regression of family income percentiles on an indicator for some college in the ACS sample, with CZ fixed effects, I find that those with some college or more have family incomes about 19.2 percentiles higher than those without college, on average. This implies that a one standard deviation increase in $\pi_{c}$ would drive only a $19.2 * 0.11=0.02$ increase in $\theta_{c}$, or less than one-third of a standard deviation of that variable. I obtain even smaller magnitudes when I use my estimates of transmission of parental income to other attainment measures. For example, column 4 of Table 6 indicates that a one standard deviation of $\pi_{c}$ is 0.0025 years of education per percentile of parental income. Column 5 of Table 3 indicates that each year of education is associated with 3.6 additional percentiles of children's income. ${ }^{16}$ Thus, a one-standard deviation increase in $\pi_{c}$

\footnotetext{
${ }^{16}$ I obtain slightly larger estimates when I use the ACS sample - 4.1 using the full sample, or 5.9 when
} 
drives an increase of $\theta_{c}$ of $0.0025 * 3.6=0.01$, or about one-sixth of a standard deviation. Although the transmission of parental income to children's income is correlated across CZs with transmission of parental income to children's educational attainment, the latter again appears not to be a primary mechanism for the former.

\subsubsection{Robustness and additional results}

The results above indicate that CZs with stronger-than-average transmission of parental income to children's income tend also to have stronger-than-average transmission of parental income to children's test scores and educational attainment, but the relationships are not large enough to account for a large share of the variation in intergenerational income transmission. This basic conclusion is robust to a variety of different specification and measurement choices, explored in the appendix.

First, Appendix Table A5 explores the sensitivity of these results to the choice of income transmission measure. Results are robust to using CHKS's measure computed for the 198385 birth cohorts, which more closely corresponds to the ELS sample, or to using the more plausibly causal measure from Chetty and Hendren (forthcoming).

Second, I show that the results are not driven by associations between parental income and children's race. CHKS document that $\theta_{c}$ is quite strongly correlated with the fraction black in the $\mathrm{CZ}$, though they also find that an alternative measure computed solely from zip codes with very few black residents is quite similar. Appendix Table A6 augments the main mixed model specifications with controls for the child's own race and gender, as well as interactions of race and gender with $\theta_{c}$. This has little effect.

Third, I explore alternative scalings of parental income and children's test scores, in Appendix Table A7. The basic result of a weak relationship between CZ-level income transmission and CZ-level transmission from parental income to children's achievement is unchanged when I measure children's test scores as z-scores or as predicted adult earnings (Bond and Lang, forthcoming), or when I measure parental income in logs or as predicted children's test scores.

very high and very low levels of attainment are trimmed. These would not change the qualitative conclusion I draw here. 
Overall, the basic results on achievement, attainment, and income transmission appear quite robust. They are suggestive that learning in school is not a key channel determining the across- $\mathrm{CZ}$ variation in income transmission, but that access to higher education may be more important.

One possibility not yet considered is that math and reading test scores do not fully capture the impacts of better childhood environments. A growing literature in recent years has documented the importance of non-cognitive skills as a component of human capital. Both the ECLS and the ELS contain batteries of questions aimed at identifying children's non-cognitive skills, and I use these to assess whether high-income-transmission CZs tend to be CZs with large gaps in non-cognitive skills between children from high- and low-income families (Appendix Table A8). Results are mixed. The $\beta$ coefficient on the parental income - CZ income transmission interaction is generally small and not statistically significant, and frequently has the wrong sign. For about half of the available measures, there is statistically significant variation across $\mathrm{CZs}$ in the return to parental income (i.e., $\sigma_{\eta} \neq 0$ ). Overall, there is little indication that non-cognitive skills are important mediators of income-toincome transmission. One set of results, however, tells a somewhat different story. In the ECLS, non-cognitive skill measures are constructed both from children's survey responses and from teacher surveys. The measures based on teacher surveys do tend to yield strong associations with income transmission. It is not clear how to account for the discrepancy between teacher surveys and student self-reports - even when the concepts overlap (e.g., for externalizing problem behaviors), results are quite different. This may indicate that hightransmission CZs tend to be CZs in which teachers are more biased in their assessments of low-income children, but this is quite speculative.

\subsection{Returns to human capital across $\mathrm{CZs}$}

The above results have concerned the role of skills - achievement, attainment, and noncognitive skills - as mediators of the intergenerational transmission of income. In terms of Figure 1, the results suggest that $\pi_{c}$ is not a primary mechanism influencing variation in reduced-form transmission $\theta_{c}$. This in turn implies that much of the variation in income transmission must be due to differences in the returns to human capital (i.e., in $\lambda_{c}$ ) or to 
direct effects of parental income on children's income not operating through human capital (i.e., to $\mu_{c}$ ).

As an initial exploration of this, I examine variation in the return to skill across CZs. As before, I estimate mixed models, in this case allowing the return to human capital to vary both with the CHKS income transmission measure and independently across CZs. These models do not isolate the relationship between income transmission and $\lambda_{c}$ from Figure 1, as to do that I would need to examine the return to skill controlling for parental income. I simply examine the reduced-form return to skill, $\tilde{\lambda}_{c}=\lambda_{c}+\frac{\sigma_{p}^{2}}{\sigma_{s}^{2}} \pi_{c} \mu_{c}$. If I find that this is strongly associated with $\theta_{c}$, that could indicate either that $\lambda_{c}$ is a major component of the across- $\mathrm{CZ}$ variation in $\theta_{c}$ or that $\mu_{c}$ is.

Table 7, Panel A presents results for a sample of 28-32 year olds surveyed in 20102012 by the American Community Survey (ACS), and assigned to their current CZs. ${ }^{17}$ Column 1 shows that each year of education, relative to the CZ mean, is associated with 5.3 percentiles of adult earnings. Columns 2-4 present models that include interactions between the individual's education and CZ-level income transmission. The interaction coefficient is positive and highly significant, indicating that the (reduced-form) return to education is larger in high-income-transmission CZs. Column 5 presents the mixed model, allowing for unexplained heterogeneity across CZs in the return to education. This heterogeneity term is substantial. The correlation between the CZ-level return to education and CZ-level income transmission is about 0.5 , comparable to the attainment transmission results earlier and much larger than that for achievement transmission. The overall variability in returns to education across CZs (i.e., in $\tilde{\lambda}_{c}$ ) is substantial, with a standard deviation of 0.7 (compared to the mean of 5.3),. Only about $30 \%$ of this attributable to $\theta_{c}$.

The lower panel of Table 7 presents a parallel analysis of returns to skill in the ELS data. Here, I combine my two human capital measures, constructing a skill index as the fitted value from a regression of children's earnings on their 12th grade math scores and indicators for each possible attainment, with CZ fixed effects. This skill index is strongly

\footnotetext{
${ }^{17}$ I censor years of education at 9 and 17. Values outside this range are unusual. The earnings-education relationship is approximately linear within this range, but not outside it. Table 7 shows results for the individual earnings percentile as the dependent variable, but results are similar when the family income percentile is used instead.
} 
related to earnings, as expected. ${ }^{18}$ It is much more strongly related in high-transmission CZs, with interaction coefficients that are notably larger than the main effects. Column 5 indicates, however, that there is a great deal of variation in the returns to skill that is orthogonal to income transmission, and the correlation between the two is only 0.3.

\section{Decomposing the across-CZ variation in income transmis- sion}

The results thus far indicate that intergenerational income transmission is positively correlated across CZs with transmission from parental income to children's test scores and educational attainment, and with the reduced-form labor market returns to human capital. Some preliminary calculations indicate that neither the achievement nor the attainment relationship is large enough, on its own, to be a primary channel in overall income transmission, but I have not yet considered them together or quantified the contribution of the returnto-skill effects. Moreover, the returns to skill estimates are reduced-form, and combine true returns to skill with any effect of parental income on children's income not operating through education (i.e., with $\mu_{c}$ ). In this section, I explore decompositions of the across-CZ variation in income transmission that address these shortcomings.

As a preliminary, I explore income-income transmission, $\theta_{c}$, in the ELS data. Measurement differences between the ELS and the tax data used by CHKS mean that the $\theta_{c} \mathrm{~s}$ implied by the ELS data differ somewhat from the tax-data-based $\theta_{c}$ s reported by CHKS - though they are nearly perfectly correlated. I also show that marriage patterns and labor force participation are quantitatively important channels for intergenerational income transmission. This motivates me to extend the three-component path diagram from Figure 1 by considering transmission into children's own earnings and into the other components of family income (spousal earnings and non-labor income) separately. I decompose the transmission of parental income to children's earnings into the three components from the

\footnotetext{
${ }^{18}$ In constructing the skill index, I measure children's earnings as a percentile of the adult income distribution, for use in my decomposition below. Thus, a child with median earnings $(\$ 22,000$ in the ELS sample) is assigned a percentile of 38 , as $\$ 22,000$ is the 38 th percentile of the family income distribution. The dependent variable in Table 7 is the percentile of the child earnings distribution, in which the same child would be assigned a percentile of 50. This explains why the coefficient is larger than one in column 1 .
} 
path diagram in Figure 1 and equation (22): (a) children's skill accumulation by the end of school; (b) returns to skills; and (c) direct effects of parental income on children's earnings not operating through observed human capital. I then separately estimate the contribution from transmission of parental income into spousal earnings and non-labor income. Figure 3 illustrates the expanded diagram.

\subsection{Income transmission in the ELS sample}

Table 8 presents mixed models, akin to those used earlier to examine transmission from parental income to children's achievement, where here the dependent variables are different components of ELS children's incomes.

In column 1, the dependent variable is the child's total family income, as a percentile of the national distribution. ${ }^{19}$ This is very nearly the same measure used by CHKS to construct their income transmission measures. Thus, we expect the $\pi_{c}$ in this specification, the CZ-level transmission of parental income to children's income in the ELS sample, to be identical to CHKS's $\theta_{c}$, but for differences in measurement between the ELS and the tax data. Indeed, I estimate a correlation of 0.99 , and $\sigma_{\eta}^{2} \approx 0$. However, the scales are somewhat different: Where one would expect an interaction coefficient $\beta=1$, I instead estimate $\hat{\beta}=0.64$ (SE 0.16 ). The implied regression of $\theta_{c}$ on $\pi_{c}$, has coefficient 1.52 , though here the expected 1 is within the confidence interval. These results might reflect the lower quality of the ELS parental income measure, relative to the tax data, ${ }^{20}$ or the fact that the ELS child income is measured at age 25, where in the tax data it is measured around age $30 . .^{21}$

Columns 2-4 replace the dependent variable with indicators (scored as 0 or 100) for positive own earnings, for being married, and for having positive spousal earnings. In each case, the interaction coefficient between parental income and CZ-level income transmission is positive and significant: In high-transmission CZs, children from high-income families are

\footnotetext{
${ }^{19}$ Appendix Table A2 presents fixed-coefficient versions of this specification.

${ }^{20}$ I have explored specifications that instrument for parental income with parental education. Although the exclusion restriction is dubious, this does raise the $\beta$ coefficient to around 1 , consistent with bias from measurement error in parental income.

${ }^{21}$ CHKS find that average income transmission is lower when children's income is measured at younger ages, but do not present evidence regarding cross- $\mathrm{CZ}$ variation.
} 
relatively more likely than children from low-income families to work, to be married, and to have a working spouse. In each case, the across-CZ correlation between income transmission and transmission of parental income to the outcome is around 0.5. Evidently, an important part of the variation in income transmission reflects labor force participation rather than solely differences in earnings conditional on participation; another important part relates to marital patterns.

Further light is shed by the gender breakdown in Panel B. CZ-level income transmission is almost perfectly correlated with the CZ-level association between parental income and daughters' labor force participation, though there is little variation across CZs in the latter.

In Column 5, I use the child's earnings as the dependent variable. Earnings are scaled here as a percentile of the family income distribution, to permit a direct comparison to column 1 (see footnote 18). The $p_{i c^{-}} \theta_{c}$ interaction coefficient is here only 0.38 (S.E. 0.14), reduced by nearly half from column 1. Evidently, a large part of the variation in measured income transmission, using CHKS's definitions, derives from components other than the child's own earnings - either spousal earnings, or non-labor income. This is particularly true for men. Column 6 adds non-labor income (for both the child and the spouse, if present) into the income measure. Results are similar to those in column 5. The key interaction coefficient remains much lower than in column 1, especially for sons.

Spousal earnings, the only component of family income included in column 1 but not column 6, are clearly an important factor. This could reflect variation across CZs in the relative likelihood that children from high- and low-income families have working spouses, as seen in column 4, but it could also reflect differences in spousal earnings distributions conditional on work, as would occur if CZs vary in the degree of assortative mating. To assess the role of the latter, I shut off any assortative matching by assigning all working spouses the same earnings. I compute the average earnings across the entire sample for working spouses, by gender - $\$ 27,000$ for women and $\$ 41,000$ for men - and use these for every working spouse in the sample, assigning 0 for those who are unmarried or have nonworking spouses. I then construct a family income as the sum of the child's actual earnings, any non-labor income, and imputed spousal earnings. As before, this sum is converted to a percentile of the actual child family income distribution. Insofar as an important part of the 
variation in income transmission reflects differences in assortative mating, we would expect the $\beta$ coefficient in column 7 to more closely resemble that in column 6 than that in column 1. This is not what I find. $\hat{\beta}$ here is even larger than in column 1. Evidently, differences in assortative mating are not contributing meaningfully to the across-CZ variation in family income transmission.

I interpret the results in Table 8 as pointing to the importance of marriage as a mechanism driving between-CZ variation in measured income transmission. Nearly one-third of the across- $\mathrm{CZ}$ variation in income transmission is explained by differences in within-CZ gradients of marriage (at the time of the age-26 ELS follow-up survey) with respect to parent income. This may represent a spurious component of the variation in $\theta_{c}$. It is not clear whether a two-earner couple should be seen as as successful as a single person with the same family income. Moreover, the median age of marriage for the ELS cohorts is around 26 (U.S. Bureau of the Census, 2004), so it is quite possible that many people who are not married at age 26 or even at 30 will be later, and will eventually be able to pool their earnings with their spouses to achieve much higher family incomes than I see in the age-26 survey.

Whether transmission operating through marriage is spurious or not, the interpretation of income-marriage transmission is quite different than that of income-earnings transmission, even though both may be statistically mediated by the child's human capital. Going forward, I separate children's family incomes into the child's own earnings and a second component combining spousal earnings and non-labor income, and I focus on the mediating role of human capital for the former.

\subsection{Decomposition of income transmission}

Table 9 presents my analysis of the decomposition of across-CZ variation in income transmission into the four components indicated in Figure 3: Skill accumulation, as moderated by the average own-earnings return to skill; returns to skill, moderated by the average parental income gradient in skill accumulation; "direct" transmission of parental income to children's earnings conditional on human capital; and spousal and non-labor income.

Column 1 presents the baseline income transmission analysis, using the family income percentile as the dependent variable. This specification is the same as in column 1 of Table 8 , 
but omits the random coefficient on parental income. Of interest is the interaction between $p_{i c}-\bar{p}_{c}$ and $\theta_{c}$. This coefficient would be identically 1 if I used the same sample and income measures as were used by CHKS in their calculation of $\theta_{c}$. My estimate is just over two-thirds of that.

Next, I decompose children's family incomes into the child's earnings and the remainder, reflecting spousal earnings and non-labor income. I scale children's earnings as a percentile of the family income distribution, as in Table 8, then scale the remaining component as the increment to the family's income percentile that is obtained by adding spousal earnings and non-labor income. Column 2 presents the analysis of children's earnings, using the same specification as in column 1. The interaction coefficient falls by nearly half, to 0.37 - as in Table 8, only a bit over half of the across-CZ variation in parental income-child income transmission is attributable to variation in parental income-child earnings transmission.

Columns 3-5 decompose the transmission into child earnings into three components, reflecting skill accumulation, returns to skills, and direct transmission, using the methods introduced in subsection 3.3. In Column 3, I show the component reflecting skill accumulation. I use the same skill index used in Table 7, combining 12th grade math scores and years of completed education, and scaled as the predicted child earnings percentile. By construction, the return to this index in child earnings, $\bar{\lambda}$, is almost identically $1 .{ }^{22}$ I repeat the random effects regression from column 2, replacing the child's actual earnings percentile with the skill index. Not surprisingly given the earlier results, the interaction term, which represents the first term of the decomposition (22), is small, and is not statistically significant. The point estimate of 0.08 implies that relative skill accumulation of children from high- and low-income families, and the earnings gap that it generates, accounts for only $11 \%$ $(=0.08 / 0.69)$ of the differences in ELS income transmission between cities with low and high values of the CHKS transmission measure.

Columns 4 and 5 explore the role of returns to skill and direct transmission, respectively. These come from a single regression of the child's actual earnings on her skill index and parental income, each interacted with $\mathrm{CZ}$ income transmission. The skill- $\theta_{c}$ interaction

\footnotetext{
${ }^{22}$ The skill index is constructed based on a weighted regression, but I estimate $\bar{\lambda}$ without weights for consistency with the unweighted random effects models in Table 9. The resulting $\hat{\bar{\lambda}}=0.99$.
} 
coefficient estimates $\frac{\partial \lambda_{c}}{\partial \theta_{c}}$; the second term of the decomposition (22) can then be obtained by multiplying it by the coefficient of parental income in a pooled regression for children's skill, $\bar{\pi}=0.09$. Thus, the second term, in column 4 , is $0.84 * 0.09=0.07$, indicating that differences in returns to skill account for another $11 \%$ of the variation in income transmission. ${ }^{23}$ The third component of the decomposition (22), in column 5 , is estimated by the parental income- $\theta_{c}$ interaction, 0.23 . This indicates that differences in the relationship between parental income and child earnings, controlling for both the child's human capital and the CZ-level return to that human capital, account for one-third of the total variation in income transmission across CZs.

Finally, column 6 presents results for the portion of family income deriving from spousal earnings and non-labor income. This is significantly more strongly related to parental income in CZs that CHKS measure as high-transmission than in those measured as low-transmission, and this accounts for $41 \%$ of the total variation in CZ-level income transmission. As Table 8 indicates, this largely reflects differences in the likelihood of being married at age 26, not differences in assortative matching.

The lower panel of Table 9 reports the decomposition separately for boys and girls. CHKS's income transmission measure better captures parent-daughter family income relationships than it does parent-son relationships. Transmission to the child's own earnings is similar for both, so represents a larger share of the total for sons. For them, returns to skills are twice as important as skill accumulation. For daughters, the return to skill is actually negatively associated with $\theta_{c}$, and skill accumulation is only trivially positively associated. All of the variation in transmission to earnings is operating through the direct component, controlling for human capital. This in part reflects variation in the relationship between parental income and daughters' labor force participation, as documented in Table 8. The contribution of spousal earnings to between- $\theta_{c}$ differences in family income transmission is about twice as large for girls as for boys. Table 8 indicates that this is largely due to a stronger role of marital status for girls, not to greater assortative mating.

\footnotetext{
${ }^{23}$ This component also captures differences in the accumulation of unobserved skills not measured by math scores or educational attainment: These are an omitted variable that is correlated with observed skill, so if some CZs have stronger gradients of unobserved skill with respect to parent income, they would appear to have higher returns to observed skill.
} 
Overall, these results make clear that differences in skill accumulation - achievement

and attainment - account for only a small share of the variation across CZs in income transmission. Marriage patterns are the largest single channel explaining family income transmission. For sons, returns to skills also play a meaningful role, while for daughters the transmission of parental income to children's earnings not mediated by human capital is more important.

\section{Conclusion}

Chetty et al.'s (2014a) pathbreaking work showed that there is dramatic variation in intergenerational income mobility across geographic areas within the United States. This raises the intriguing possibility that we can identify policies that account for this variation and, by exporting these policies from high- to low-mobility areas, move closer to equality of opportunity.

CHKS presented suggestive correlations indicating that school quality might be an important contributing factor. This paper has investigated this suggestion by asking whether high- and low-income children's academic outcomes are more equal in areas where their adult economic outcomes are more equal. I find that there is statistically significant variation across commuting zones in the gradients of educational attainment, academic achievement, and non-cognitive skills with respect to parental income. This variation is positively correlated with variation in income transmission across $\mathrm{CZs}$, but the correlations are modest. Moreover, while substantial, the variation in human capital transmission is not large enough in magnitude to be a primary mechanism by which income is transmitted across generations.

I find that only about one-ninth of the across-CZ variation in intergenerational income mobility is attributable to differences in children's earnings deriving from differences in the accumulation of observed skills. A similar share is attributable to differences in the labor market returns to children's skills. About one-third is attributable to differences in the labor market return to parental income holding skills (and the returns to skills) constant. The remaining, largest portion derives from differences in spousal and non-labor income, primarily reflecting differences in the likelihood of having a working spouse. 
Together, these facts indicate that the education system makes only a modest contribution to variation in intergenerational income transmission. The evidence points to other factors as potentially more important, including cultural tendencies toward early marriage and local labor market factors that influence the labor force participation rate and the ability of children from high-income families to match into high-earnings jobs conditional on their education and skills.

This is not to say that school quality is not important for other reasons, of course, or even that it does not contribute to overall mobility in a way that is roughly constant across CZs. Nevertheless, further investigation into determinants of local intergenerational mobility should expand from a near-exclusive focus on education to other potential mechanisms. One area for further attention is differences in the likelihood of marriage, either because CZs vary in the likelihood that romantic partners will be formally married or because of variation in partnership rates. In terms of earnings outcomes, other areas of interest include local income inequality and labor market institutions that influence it (e.g., unions), and factors influencing the strength of local labor market networks and the spatial and social stratification of the local market. 


\section{References}

Aaronson, Daniel and Bhashkar Mazumder, "Intergenerational economic mobility in the United States, 1940 to 2000," Journal of Human Resources, 2008, 43 (1), 139-172.

Bond, Timothy N. and Kevin Lang, "The evolution of the Black-White test score gap in Grades K-3: The fragility of results," Review of Economics and Statistics, 2013, 95 (5), $1468-1479$.

_ and _ , "The black-white education-scaled test-score gap in grades $\mathrm{K}-7$," Journal of Human Resources, forthcoming. June 2017.

Bradbury, Bruce, Miles Corak, Jane Waldfogel, and Elizabeth Washbrook, Too many children left behind: The US achievement gap in comparative perspective, Russell Sage Foundation, 2015.

Chetty, Raj and Nathaniel Hendren, "The impacts of neighborhoods on intergenerational mobility II: County-level estimates," Quarterly Journal of Economics, forthcoming. December 2017.

_, _, Patrick Kline, and Emmanuel Saez, "Where is the land of opportunity? The geography of intergenerational mobility in the United States," The Quarterly Journal of Economics, 2014, 129 (4), 1553-1623.

$\ldots, \ldots, \ldots$, , and Nicholas Turner, "Is the United States still a land of opportunity? Recent trends in intergenerational mobility," The American Economic Review, 2014, 104 (5), 141-147.

Gelman, Andrew and Jennifer Hill, Data analysis using regression and multilevel/hierarchical models, Cambridge University Press, 2006.

Ingels, Steven J., Daniel J. Pratt, Christopher P. Alexander, Donna M. Jewell, Erich Lauff, Tiffany Mattox, and David Wilson, "Education Longitudinal Study of 2002 Third Follow-up Data File Documentation," Technical Report NCES 2014-364), National Center for Education Statistics, Institute of Education Sciences, U.S. Department of Education, Washington, DC 2014.

_, _, Deborah R. Herget, Jill A. Dever, Laura Burns Fritch, James E. Ottem Randolph andRogers, Sami Kitmitto, and Steve Leinwand, "High School Longitudinal Study of 2009 (HSLS:09) Base Year to First Follow-Up Data File Documentation," Technical Report NCES 2014-361, National Center for Education Statistics, Institute of Education Sciences, U.S. Department of Education, Washington, DC 2014.

Jacob, Brian and Jesse Rothstein, "The measurement of student ability in modern assessment systems," Journal of Economic Perspectives, Summer 2016, 30 (3), 85-108.

Kearney, Melissa S and Phillip B Levine, "Income inequality and early nonmarital childbearing," Journal of Human Resources, 2014, 49 (1), 1-31.

_ and _ , "Income inequality, social mobility, and the decision to drop out of high school," Brookings Papers on Economic Activity, 2016, p. 367. 
National Center for Education Statistics, "ELS:2012 Student Codebook," Technical Report undated. Retrieved from http://nces.ed.gov/pubs2014/ELS2012_codebook_ Student1.pdf on April 6, 2017.

Tourangeau, Karen, Christine Nord, Thanh Lê, Alberto G. Sorongon, and Michelle Najarian, "Early Childhood Longitudinal Study, Kindergarten Class of 199899 (ECLS-K), Combined User's Manual for the ECLS-K Eighth-Grade and K-8 Full Sample Data Files and Electronic Codebooks," Technical Report NCES 2009-004, National Center for Education Statistics, Institute of Education Sciences, U.S. Department of Education, Washington, DC 2009.

_, _, _, Judith M. Pollack, and Sally Atkins-Burnett, "Early Childhood Longitudinal Study, Kindergarten Class of 1998-99 (ECLS-K), Combined User's Manual for the ECLS-K Fifth-Grade Data Files and Electronic Codebooks," Technical Report NCES 2006-032, National Center for Education Statistics, U.S. Department of Education, Washington D.C. 2006.

U.S. Bureau of the Census, "Table MS-2. Estimated Median Age at First Marriage, by Sex: 1890 to Present. https://www.census.gov/population/socdemo/hh-fam/tabMS2.pdf," Technical Report September 152004. 
Figure 1. Path diagram of the transmission of parental income to child income, mediated by the child's human capital.

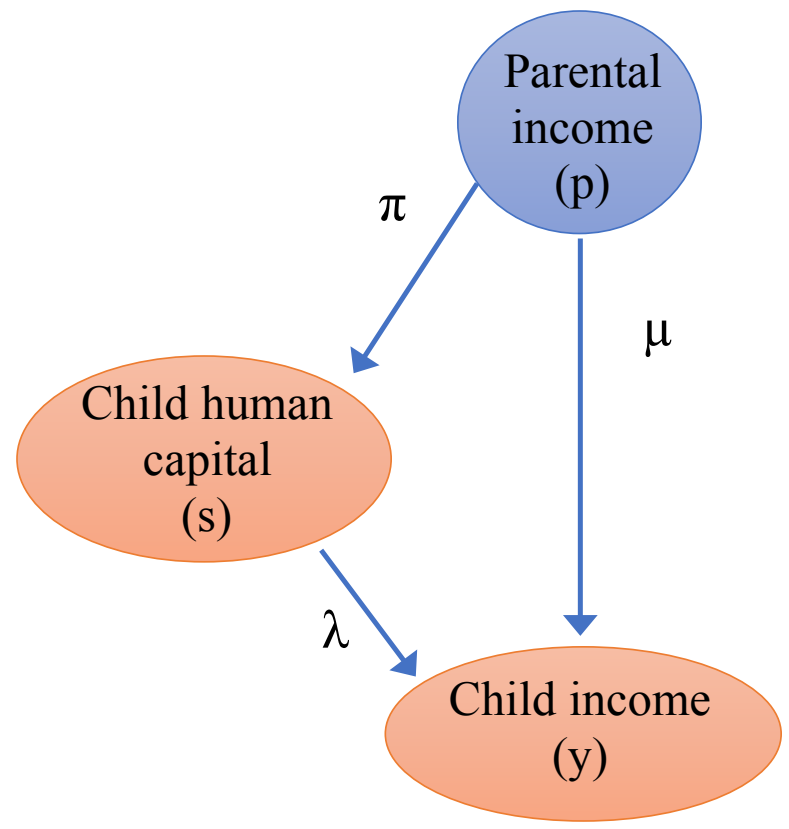

Total transmission is $\theta=\pi \lambda+\mu$ 
Figure 2. Parental income - child test score transmission, by $\mathrm{CZ}$ income transmission $(\theta)$ decile

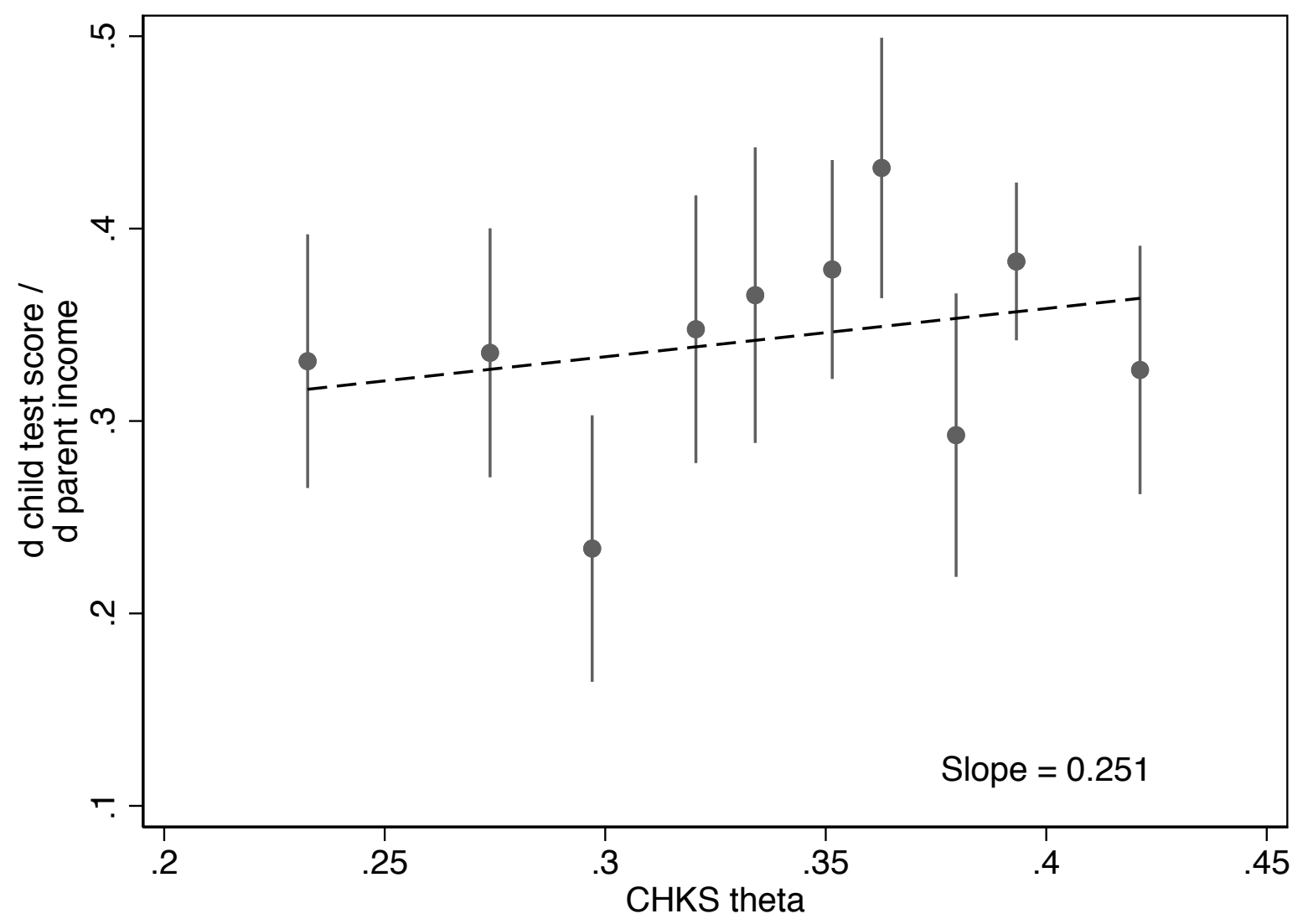

Notes: CZs are divided into deciles based on CHKS's income transmission (relative mobility) measure. Figure plots coefficients and 95\% confidence intervals for regressions of child test score percentiles on parent income percentiles, estimated separately for each decile. Regressions include CZ fixed effects and use ELS sampling weights. Dashed line shows an unweighted regression of the decile coefficient on the decile mean income transmission; its slope is shown in the lower right. 
Figure 3. Path diagram with spousal earnings and non-labor income

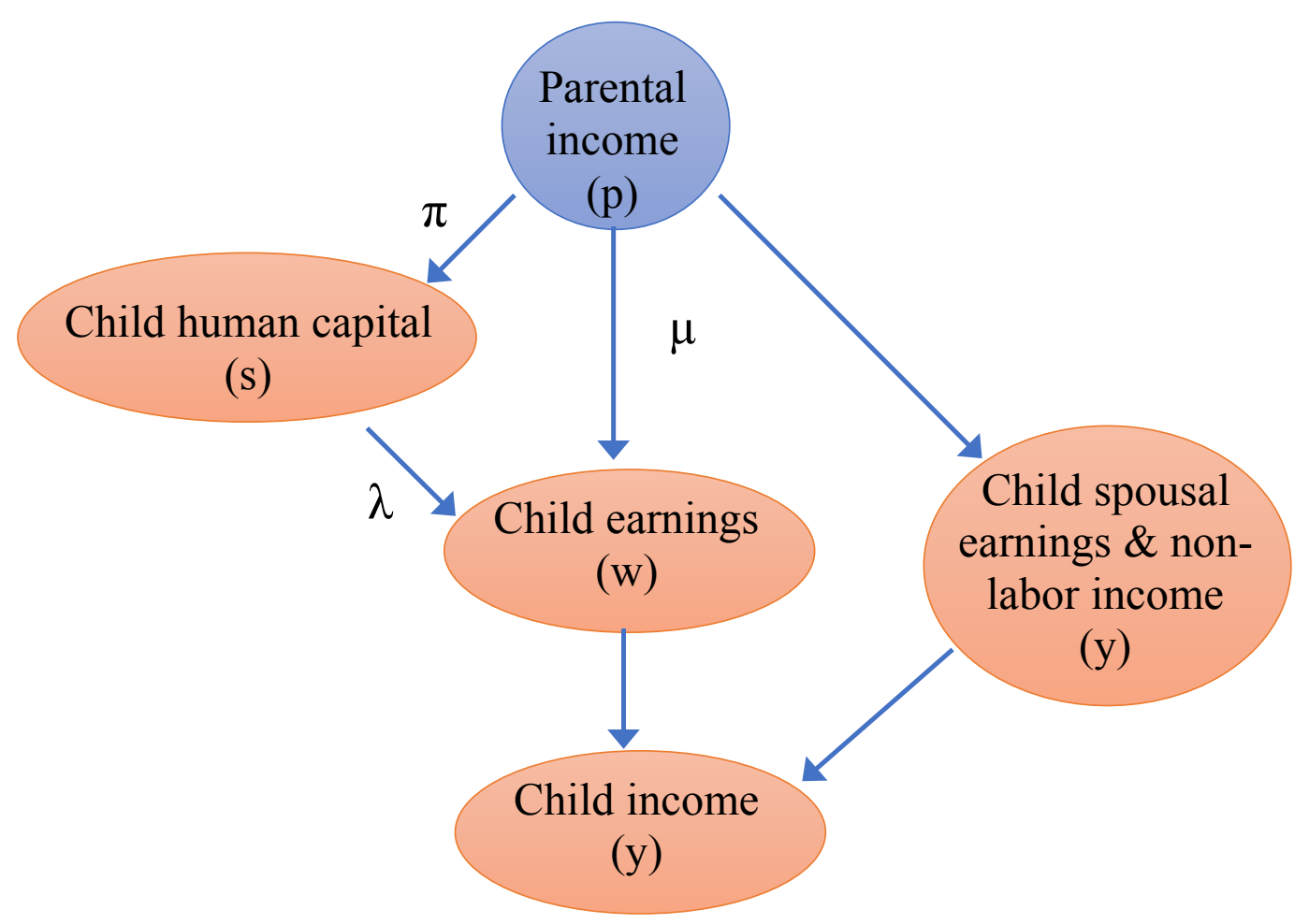


Table 1. Summary statistics for CZ-level relative mobility (income transmission)

\begin{tabular}{|c|c|c|c|c|}
\hline & \multicolumn{2}{|r|}{ Full sample } & \multicolumn{2}{|r|}{100 largest $\mathrm{CZs}$} \\
\hline & $(1)$ & $(2)$ & (3) & (4) \\
\hline $\mathrm{N}$ & 709 & & 100 & \\
\hline Mean & 0.325 & & 0.338 & \\
\hline Standard deviation & 0.065 & & 0.054 & \\
\hline Minimum & 0.068 & Linton, ND & 0.215 & Santa Barbara, CA \\
\hline 10th percentile & 0.240 & Hutchinson, MN & 0.257 & Bakersfield, CA \\
\hline 25th percentile & 0.280 & Carroll, IA & 0.298 & Manchester, NH \\
\hline 50th percentile & 0.330 & Eagle Butte, SD & 0.348 & Des Moines, IA \\
\hline 75th percentile & 0.373 & Roanoke, VA & 0.382 & Greenville, SC \\
\hline 90th percentile & 0.404 & Vicksburg, MS & 0.398 & Indianapolis, IN \\
\hline Maximum & 0.508 & Lake Providence, LA & 0.429 & Cincinnati, $\mathrm{OH}$ \\
\hline Correlations & & & & \\
\hline $\begin{array}{l}\text { (1) Relative mobility for } 1983-85 \\
\text { birth cohorts } \\
\text { (2) Causal mobility measure from }\end{array}$ & 0.84 & & 0.98 & \\
\hline Chetty-Hendren & 0.85 & & 0.91 & \\
\hline $\begin{array}{l}\text { (3) Relative mobility for college } \\
\text { enrollment }\end{array}$ & 0.68 & & 0.70 & \\
\hline
\end{tabular}

Notes: Statistics are computed at the CZ level, without weights, and pertain to the preferred "relative mobility" measure from Chetty et al. (2014). Correlation 1 is with the relative mobility measure for the 1983-1985 birth cohorts, from Chetty et al. (2014). Correlation 2 is with the causal mobility measure from Chetty and Hendren (forthcoming). Correlation 3 is with CZ-level income-college enrollment transmission - the slope of college enrollment between 18 and 21 with respect to parental income percentile - for the 1980-1982 birth cohorts, from Chetty et al. (2014). 
Table 2. Summary statistics for individual-level samples

\begin{tabular}{|c|c|c|c|c|}
\hline & $\begin{array}{c}\text { Educational } \\
\text { Longitudinal } \\
\text { Study } \\
\text { (ELS) }\end{array}$ & $\begin{array}{l}\text { Early Childhood } \\
\text { Longitudinal } \\
\text { Study } \\
\text { (ECLS) } \\
\end{array}$ & $\begin{array}{c}\text { High School } \\
\text { Longitudinal } \\
\text { Study } \\
\text { (HSLS) }\end{array}$ & $\begin{array}{c}\text { American } \\
\text { Community } \\
\text { Survey } \\
\text { (ACS) }\end{array}$ \\
\hline & (1) & $(2)$ & (3) & (4) \\
\hline Birth year & 1985-1986 & $1992-1993$ & 1994-1995 & 1980-1982 \\
\hline Number of observations & 15,240 & 19,940 & 21,440 & 330,366 \\
\hline \# of CZs & 312 & 365 & 295 & 488 \\
\hline Female & 0.50 & 0.48 & 0.50 & 0.50 \\
\hline Black & 0.14 & 0.18 & 0.17 & 0.14 \\
\hline Hispanic & 0.16 & 0.19 & 0.22 & 0.21 \\
\hline Asian & 0.04 & 0.03 & 0.03 & 0.06 \\
\hline Other non-white & 0.05 & 0.02 & 0.08 & 0.09 \\
\hline Parent income & $\begin{array}{c}61,417 \\
(50,312)\end{array}$ & $\begin{array}{c}51,789 \\
(47,419)\end{array}$ & $\begin{array}{c}70,464 \\
(56,034)\end{array}$ & \\
\hline Test scores available for grades & 10,12 & $\mathrm{~K}, 1,2,3,5,8$ & 9,11 & $\mathrm{n} / \mathrm{a}$ \\
\hline Post-high school outcomes & Age 26 & & & Age $28-32$ \\
\hline Any college & 0.84 & & & 0.53 \\
\hline College completion (BA degree) & 0.33 & & & 0.22 \\
\hline Years of education & $\begin{array}{l}14.0 \\
(1.8)\end{array}$ & & & $\begin{array}{l}13.3 \\
(2.8)\end{array}$ \\
\hline Marital status & 0.28 & & & 0.47 \\
\hline Presence of working spouse & 0.24 & & & 0.40 \\
\hline Earnings & $\begin{array}{c}25,451 \\
(24,672)\end{array}$ & & & $\begin{array}{c}29,508 \\
(32,477)\end{array}$ \\
\hline Family income & $\begin{array}{c}36,095 \\
(35,238)\end{array}$ & & & $\begin{array}{c}73,039 \\
(62,890)\end{array}$ \\
\hline
\end{tabular}

Note: Sample sizes and demographics are computed for the base-year sample for each survey, and use sampling weights. Sample sizes in columns 1-3 are rounded to the nearest 10. Standard deviations in parentheses. 
Table 3. Income transmission mediation analysis at the national level (ELS)

\begin{tabular}{|c|c|c|c|c|c|c|c|}
\hline \multirow[t]{2}{*}{ Dependent variable: } & \multirow{2}{*}{$\begin{array}{c}\begin{array}{c}\text { 12th grade math } \\
\text { score (percentile) }\end{array} \\
(1)\end{array}$} & \multirow{2}{*}{$\begin{array}{c}\begin{array}{c}\text { Years of } \\
\text { education }\end{array} \\
(2) \\
\end{array}$} & \multicolumn{5}{|c|}{ Family income (percentile) } \\
\hline & & & (3) & (4) & (5) & (6) & (7) \\
\hline Parents' income (percentile) & $\begin{array}{c}0.35 \\
(0.01)\end{array}$ & $\begin{array}{c}0.019 \\
(0.001)\end{array}$ & $\begin{array}{c}0.16 \\
(0.01)\end{array}$ & & & & $\begin{array}{c}0.07 \\
(0.01)\end{array}$ \\
\hline 12th grade math score (percentile) & & & & $\begin{array}{c}0.24 \\
(0.01)\end{array}$ & & $\begin{array}{c}0.18 \\
(0.02)\end{array}$ & $\begin{array}{c}0.17 \\
(0.02)\end{array}$ \\
\hline Years of education & & & & & $\begin{array}{c}3.59 \\
(0.19)\end{array}$ & $\begin{array}{l}1.76 \\
(0.24)\end{array}$ & $\begin{array}{c}1.61 \\
(0.24)\end{array}$ \\
\hline $\mathrm{N}$ & 13,650 & 13,250 & 11,510 & 9,980 & 11,510 & 9,980 & 9,980 \\
\hline $\mathrm{R}^{2}$ & 0.19 & 0.15 & 0.08 & 0.11 & 0.10 & 0.12 & 0.12 \\
\hline
\end{tabular}

Notes: Parental income, child family income, and 12th grade math scores are measured in percentiles of the national distribution and range from 0 to 100. All regressions use ELS sample weights (for the wave-1 survey in column 1, and for the wage-3 survey in columns 2-7) and include CZ fixed effects. Standard errors are clustered at the CZ level. Sample sizes are rounded to the nearest 10 . 
Table 4. Transmission of parental income to children's $12^{\text {th }}$ grade math achievement (ELS)

\begin{tabular}{|c|c|c|c|c|c|}
\hline & $(1)$ & $(2)$ & (3) & $(4)$ & $(5)$ \\
\hline \multirow[t]{2}{*}{ Parental income - CZ mean } & 0.35 & 0.35 & 0.34 & 0.35 & 0.33 \\
\hline & $(0.01)$ & $(0.01)$ & $(0.01)$ & $(0.01)$ & $(0.01)$ \\
\hline \multirow[t]{2}{*}{$\mathrm{CZ}$ mean parental income } & 0.69 & 0.69 & 0.70 & & 0.70 \\
\hline & $(0.04)$ & $(0.04)$ & $(0.04)$ & & $(0.04)$ \\
\hline \multirow[t]{2}{*}{$\mathrm{CZ}$ income transmission $(\theta)$} & & -97.0 & -74.4 & & -72.6 \\
\hline & & $(26.4)$ & $(28.1)$ & & $(27.8)$ \\
\hline (Parental income - $\mathrm{CZ}$ mean) & & 0.32 & 0.37 & 0.32 & 0.41 \\
\hline * CZ income transmission $(\theta)$ & & $(0.21)$ & $(0.15)$ & $(0.21)$ & $(0.17)$ \\
\hline $\mathrm{CZ}$ mean parental income & & 1.75 & 1.23 & & 1.20 \\
\hline * CZ income transmission $(\theta)$ & & $(0.53)$ & $(0.57)$ & & $(0.56)$ \\
\hline \multirow[t]{2}{*}{ SD of parental income random coefficient $(\eta)$} & & & & & 0.07 \\
\hline & & & & & $(0.02)$ \\
\hline $\mathrm{CZ}$ effects & None & None & $\mathrm{RE}$ & FE & RE \\
\hline \multicolumn{6}{|l|}{ Across-CZ distribution: } \\
\hline SD of CZ income transmission $(\theta)$ & & 0.057 & 0.057 & 0.057 & 0.057 \\
\hline SD of parental income-test score transmission $(\pi)$ & & 0.018 & 0.021 & 0.018 & 0.072 \\
\hline \multirow[t]{2}{*}{ Coefficient of between- $\mathrm{CZ}$ regression of $\theta$ on $\pi$} & & & & & 0.26 \\
\hline & & & & & $(0.12)$ \\
\hline $\mathrm{R}^{2}$ & & & & & 0.11 \\
\hline $\operatorname{Corr}(\theta, \pi)$ & & 1 & 1 & 1 & 0.32 \\
\hline p-value, $\operatorname{SD}(\eta)=0 / \operatorname{corr}(\theta, \pi)=1$ (LR test) & & & & & $<0.01$ \\
\hline
\end{tabular}

Notes: Dependent variable in each column is the 12 th grade math score, in national percentile units (0-100). Parental income is also measured in percentiles (0-100). CZ income transmission is the relative mobility measure for the 1980-82 birth cohorts from Chetty et al. (2014), demeaned across CZs. Specifications labeled "RE" and "FE" include CZ random effects and fixed effects, respectively. RE specification in column 3 is estimated via GLS; mixed model in column 5 is estimated by maximum likelihood. Specifications in columns 1, 2, and 4 are weighted using ELS sampling weights; columns 3 and 5 are unweighted. Standard errors are clustered at the $\mathrm{CZ}$ level. $\mathrm{p}$-value in column 5 is for a likelihood ratio test of the mixed model against a random effects model with fixed coefficients (as in column 3, though estimated by maximum likelihood rather than GLS). Number of observations (rounded to the nearest 10) $=$ 13,650 . 
Table 5. Parental income-child achievement transmission across grades, cohorts, and subjects

\begin{tabular}{|c|c|c|c|c|c|c|c|}
\hline & & $\begin{array}{c}\text { Parental } \\
\text { income }\end{array}$ & $\begin{array}{c}\text { Parental } \\
\text { income } * \mathrm{CZ} \\
\text { income } \\
\text { transmission }\end{array}$ & $\begin{array}{l}\text { SD of parental } \\
\text { income random } \\
\text { coefficient }(\eta)\end{array}$ & $\begin{array}{l}\text { Coefficient of } \\
\text { regression of income } \\
\text { transmission }(\theta) \text { on } \\
\text { test score } \\
\text { transmission }(\pi)\end{array}$ & $\operatorname{Corr}(\theta, \pi)$ & $\begin{array}{c}\text { p-value, } \\
\text { LR test of } \\
\operatorname{SD}(\eta)=0\end{array}$ \\
\hline & & (1) & (2) & (3) & (4) & (5) & (6) \\
\hline \multicolumn{8}{|c|}{ Panel A: Math scores } \\
\hline ECLS & K (spring) & $\begin{array}{c}0.35 \\
(0.01)\end{array}$ & $\begin{array}{c}0.33 \\
(0.25)\end{array}$ & $\begin{array}{c}0.08 \\
(0.01)\end{array}$ & $\begin{array}{c}0.17 \\
(0.13)\end{array}$ & 0.24 & $<0.01$ \\
\hline ECLS & G1 (spring) & $\begin{array}{c}0.35 \\
(0.01)\end{array}$ & $\begin{array}{c}0.08 \\
(0.24)\end{array}$ & $\begin{array}{c}0.06 \\
(0.01)\end{array}$ & $\begin{array}{c}0.09 \\
(0.29)\end{array}$ & 0.08 & $<0.01$ \\
\hline ECLS & G3 & $\begin{array}{c}0.42 \\
(0.01)\end{array}$ & $\begin{array}{c}0.13 \\
(0.23)\end{array}$ & $\begin{array}{c}0.08 \\
(0.01)\end{array}$ & $\begin{array}{c}0.08 \\
(0.14)\end{array}$ & 0.10 & $<0.01$ \\
\hline ECLS & G5 & $\begin{array}{c}0.39 \\
(0.01)\end{array}$ & $\begin{array}{c}0.31 \\
(0.26)\end{array}$ & $\begin{array}{c}0.09 \\
(0.01)\end{array}$ & $\begin{array}{c}0.13 \\
(0.11)\end{array}$ & 0.20 & $<0.01$ \\
\hline ECLS & G8 & $\begin{array}{c}0.41 \\
(0.01)\end{array}$ & $\begin{array}{c}0.22 \\
(0.22)\end{array}$ & $\begin{array}{c}0.07 \\
(0.02)\end{array}$ & $\begin{array}{c}0.16 \\
(0.17)\end{array}$ & 0.19 & 0.01 \\
\hline HSLS & G9 & $\begin{array}{c}0.30 \\
(0.01)\end{array}$ & $\begin{array}{c}0.30 \\
(0.17)\end{array}$ & $\begin{array}{c}0.05 \\
(0.01)\end{array}$ & $\begin{array}{c}0.33 \\
(0.19)\end{array}$ & 0.32 & 0.02 \\
\hline HSLS & G11 & $\begin{array}{c}0.28 \\
(0.01)\end{array}$ & $\begin{array}{c}0.60 \\
(0.18)\end{array}$ & $\begin{array}{c}0.07 \\
(0.01)\end{array}$ & $\begin{array}{c}0.30 \\
(0.09)\end{array}$ & 0.43 & $<0.01$ \\
\hline ELS & G10 & $\begin{array}{c}0.31 \\
(0.01)\end{array}$ & $\begin{array}{c}0.37 \\
(0.16)\end{array}$ & $\begin{array}{c}0.06 \\
(0.01)\end{array}$ & $\begin{array}{c}0.29 \\
(0.13)\end{array}$ & 0.33 & $<0.01$ \\
\hline ELS & G12 & $\begin{array}{c}0.33 \\
(0.01)\end{array}$ & $\begin{array}{c}0.41 \\
(0.17)\end{array}$ & $\begin{array}{c}0.07 \\
(0.02)\end{array}$ & $\begin{array}{c}0.26 \\
(0.12)\end{array}$ & 0.32 & $<0.01$ \\
\hline \multicolumn{8}{|c|}{ Panel B: Reading scores } \\
\hline ECLS & $\mathrm{K}$ (spring) & $\begin{array}{c}0.38 \\
(0.01)\end{array}$ & $\begin{array}{c}0.16 \\
(0.23)\end{array}$ & $\begin{array}{c}0.08 \\
(0.01)\end{array}$ & $\begin{array}{c}0.09 \\
(0.14)\end{array}$ & 0.12 & $<0.01$ \\
\hline ECLS & G1 (spring) & $\begin{array}{c}0.38 \\
(0.01)\end{array}$ & $\begin{array}{c}0.23 \\
(0.22)\end{array}$ & $\begin{array}{c}0.06 \\
(0.01)\end{array}$ & $\begin{array}{c}0.21 \\
(0.20)\end{array}$ & 0.22 & $<0.01$ \\
\hline ECLS & G3 & $\begin{array}{c}0.40 \\
(0.01)\end{array}$ & $\begin{array}{c}0.41 \\
(0.21)\end{array}$ & $\begin{array}{c}0.06 \\
(0.02)\end{array}$ & $\begin{array}{c}0.33 \\
(0.19)\end{array}$ & 0.37 & $<0.01$ \\
\hline ECLS & G5 & $\begin{array}{c}0.39 \\
(0.01)\end{array}$ & $\begin{array}{c}0.48 \\
(0.21)\end{array}$ & $\begin{array}{c}0.06 \\
(0.01)\end{array}$ & $\begin{array}{c}0.37 \\
(0.15)\end{array}$ & 0.42 & $<0.01$ \\
\hline ECLS & G8 & $\begin{array}{c}0.39 \\
(0.01)\end{array}$ & $\begin{array}{c}0.33 \\
(0.21)\end{array}$ & $\begin{array}{c}0.05 \\
(0.02)\end{array}$ & $\begin{array}{c}0.48 \\
(0.35)\end{array}$ & 0.40 & 0.21 \\
\hline ELS & G10 & $\begin{array}{c}0.30 \\
(0.01)\end{array}$ & $\begin{array}{c}0.25 \\
(0.18)\end{array}$ & $\begin{array}{c}0.07 \\
(0.01)\end{array}$ & $\begin{array}{c}0.15 \\
(0.11)\end{array}$ & 0.19 & $<0.01$ \\
\hline
\end{tabular}

Notes: Each row presents statistics from a single mixed model pertaining to a different test score (for a given sample, grade, and subject), each scaled as national percentile units (0-100). Parent incomes in columns 1-3 are percentiles, deviated from the CZ mean. Specifications are as in Table 4, column 5. See notes to Table 4 for details. Number of observations (rounded to the nearest 10) ranges between 9,140 and 20,430. 
Table 6. Parental income - child educational attainment transmission (ELS)

\begin{tabular}{|c|c|c|c|c|}
\hline & \multicolumn{2}{|c|}{$\begin{array}{c}\text { College } \\
\text { graduation } \\
(0 / 100) \\
\end{array}$} & \multicolumn{2}{|c|}{$\begin{array}{c}\text { Years of } \\
\text { education at } 26 \\
(* 100)\end{array}$} \\
\hline & $(1)$ & $(2)$ & $(3)$ & $(4)$ \\
\hline Parental income - CZ mean & $\begin{array}{c}0.45 \\
(0.02)\end{array}$ & $\begin{array}{c}0.45 \\
(0.02)\end{array}$ & $\begin{array}{c}1.85 \\
(0.06)\end{array}$ & $\begin{array}{c}1.86 \\
(0.06)\end{array}$ \\
\hline $\begin{array}{l}\text { (Parental income - CZ mean) } \\
\quad * \mathrm{CZ} \text { income transmission }(\theta)\end{array}$ & $\begin{array}{c}0.64 \\
(0.30)\end{array}$ & $\begin{array}{c}0.74 \\
(0.29)\end{array}$ & $\begin{array}{c}2.30 \\
(1.12)\end{array}$ & $\begin{array}{l}2.35 \\
(1.09)\end{array}$ \\
\hline SD of parental income random coefficient $(\eta)$ & & $\begin{array}{c}0.08 \\
(0.03)\end{array}$ & & $\begin{array}{c}0.22 \\
(0.13)\end{array}$ \\
\hline \multicolumn{5}{|l|}{ Across-CZ distribution: } \\
\hline $\mathrm{SD}$ of CZ income transmission $(\theta)$ & 0.056 & 0.056 & 0.056 & 0.056 \\
\hline SD of parental income-test score transmission $(\pi)$ & 0.036 & 0.086 & 0.130 & 0.254 \\
\hline Coefficient of between- $\mathrm{CZ}$ regression of $\theta$ on $\pi$ & & $\begin{array}{c}0.32 \\
(0.19)\end{array}$ & & $\begin{array}{c}0.12 \\
(0.11)\end{array}$ \\
\hline $\mathrm{R}^{2}$ & & 0.24 & & 0.27 \\
\hline $\operatorname{Corr}(\theta, \pi)$ & 1 & 0.49 & 1 & 0.52 \\
\hline p-value, $\operatorname{SD}(\eta)=0 / \operatorname{corr}(\theta, \pi)=1$ (LR test) & & 0.15 & & 0.33 \\
\hline
\end{tabular}

Notes: Specifications in columns 1 and 3 are as in Table 4, column 3; those in columns 2 and 4 are as in Table 4, column 5. All columns include controls for CZ mean parental income, CZ income transmission, and their interaction. See notes to Table 4 for details. Dependent variable in columns 1-2 is scaled as 0 for failures and 100 for successes; in columns 3-4, dependent variable is years of education multiplied by 100. Standard errors are clustered at the CZ level. Number of observations (rounded to the nearest 10) $=13,250$. 
Table 7. Returns to education in the ACS and ELS samples

\begin{tabular}{|c|c|c|c|c|c|}
\hline & $(1)$ & $(2)$ & $(3)$ & $(4)$ & $(5)$ \\
\hline \multicolumn{6}{|c|}{ Panel A: Returns to education in American Community Survev (ACS) data } \\
\hline \multirow[t]{2}{*}{ Years of education - CZ mean } & 5.34 & 5.35 & 5.53 & 5.35 & 5.18 \\
\hline & $(0.08)$ & $(0.08)$ & $(0.07)$ & $(0.08)$ & $(0.05)$ \\
\hline \multirow[t]{2}{*}{ * CZ income transmission $(\theta)$} & & 3.97 & 4.58 & 3.97 & 6.95 \\
\hline & & $(1.05)$ & $(1.04)$ & $(1.05)$ & $(0.94)$ \\
\hline \multirow[t]{2}{*}{ SD of education random coefficient $(\eta)$} & & & & & 0.62 \\
\hline & & & & & $(0.04)$ \\
\hline CZ controls & None & None & $\mathrm{RE}$ & $\mathrm{FE}$ & $\mathrm{RE}$ \\
\hline \multicolumn{6}{|l|}{ Across-CZ distribution: } \\
\hline SD of CZ income transmission $(\theta)$ & & 0.056 & 0.056 & 0.056 & 0.056 \\
\hline SD of return to education $(\tilde{\lambda})$ & & 0.222 & 0.256 & 0.222 & 0.728 \\
\hline \multirow[t]{2}{*}{ Coefficient of between-CZ regression of $\theta$ on $\tilde{\lambda}$} & & & & & 0.04 \\
\hline & & & & & $(0.00)$ \\
\hline $\mathrm{R}^{2}$ & & & & & 0.29 \\
\hline $\operatorname{Corr}(\theta, \tilde{\lambda})$ & & 1 & 1 & 1 & 0.53 \\
\hline p-value, $\operatorname{SD}(\eta)=0 / \operatorname{corr}(\theta, \tilde{\lambda})=1$ (LR test) & & & & & $<0.01$ \\
\hline \multicolumn{6}{|c|}{ Panel B: Returns to skills in Educational Longitudinal Survey (ELS) data } \\
\hline \multirow[t]{2}{*}{ Skill index - CZ mean } & 1.09 & 1.09 & 1.07 & 1.06 & 1.08 \\
\hline & $(0.04)$ & $(0.04)$ & $(0.04)$ & $(0.04)$ & $(0.04)$ \\
\hline \multirow[t]{2}{*}{ * CZ income transmission $(\theta)$} & & 2.30 & 1.28 & 2.30 & 1.26 \\
\hline & & $(0.67)$ & $(0.66)$ & $(0.68)$ & $(0.73)$ \\
\hline \multirow[t]{2}{*}{ SD of skill index random coefficient $(\eta)$} & & & & & 0.21 \\
\hline & & & & & $(0.07)$ \\
\hline $\mathrm{CZ}$ controls & None & None & $\mathrm{RE}$ & $\mathrm{FE}$ & $\mathrm{RE}$ \\
\hline \multicolumn{6}{|l|}{ Across-CZ distribution: } \\
\hline SD of CZ income transmission $(\theta)$ & & 0.057 & 0.057 & 0.057 & 0.057 \\
\hline SD of return to education $(\tilde{\lambda})$ & & 0.130 & 0.072 & 0.130 & 0.219 \\
\hline \multirow[t]{2}{*}{ Coefficient of between- $\mathrm{CZ}$ regression of $\theta$ on $\tilde{\lambda}$} & & & & & 0.08 \\
\hline & & & & & $(0.07)$ \\
\hline $\mathrm{R}^{2}$ & & & & & 0.10 \\
\hline $\operatorname{Corr}(\theta, \tilde{\lambda})$ & & 1 & 1 & 1 & 0.32 \\
\hline p-value, $\operatorname{SD}(\eta)=0 / \operatorname{corr}(\theta, \tilde{\lambda})=1$ (LR test) & & & & & 0.14 \\
\hline
\end{tabular}

Notes: In Panel A, sample consists of individuals born 1980-1982 in the ACS 2010-2012 one-year public use microdata samples $(\mathrm{N}=241,670)$. Respondents are assigned to their $\mathrm{CZ}$ of current residence.

Dependent variable is the child's earnings percentile (0-100). Years of education is naturally coded, with values below 9 or above 17 set to missing. In Panel B, sample is ELS sample (N=9,980). Skill index is the fitted value from a regression of children's earnings at age 25, scaled as a percentile of the family income distribution, on their $12^{\text {th }}$ grade math score percentile and dummies for years of schooling completed, with CZ fixed effects. Specifications match the corresponding columns of Table 4. Columns 2, 3, and 5 include controls for CZ mean years of education (panel A) or skill index (panel B), the CZ income transmission, and their interaction; coefficients on CZ-level covariates are not reported. See notes to Table 4 for details. 
Table 8. Transmission of parental income to children's income, earnings, and marital status

\begin{tabular}{|c|c|c|c|c|c|c|c|}
\hline & $\begin{array}{l}\text { Child } \\
\text { family } \\
\text { income }\end{array}$ & $\begin{array}{c}\text { Own } \\
\text { earnings } \\
>0 \\
(0 / 100)\end{array}$ & $\begin{array}{c}\text { Marital } \\
\text { status } \\
(0 / 100)\end{array}$ & $\begin{array}{l}\text { Working } \\
\text { spouse } \\
(0 / 100)\end{array}$ & $\begin{array}{l}\text { Child } \\
\text { earnings }\end{array}$ & $\begin{array}{c}\text { Child } \\
\text { earnings }+ \\
\text { nonlabor } \\
\text { income }\end{array}$ & $\begin{array}{l}\text { Child earnings }+ \\
\text { non-labor income } \\
\quad+\text { imputed } \\
\text { spousal earnings }\end{array}$ \\
\hline & $(1)$ & $(2)$ & (3) & (4) & $(5)$ & $(6)$ & (7) \\
\hline \multicolumn{8}{|l|}{ Panel A: Full sample } \\
\hline Parental income - CZ mean & $\begin{array}{c}0.17 \\
(0.01)\end{array}$ & $\begin{array}{c}0.15 \\
(0.01)\end{array}$ & $\begin{array}{c}0.00 \\
(0.01)\end{array}$ & $\begin{array}{c}0.01 \\
(0.01)\end{array}$ & $\begin{array}{c}0.15 \\
(0.01)\end{array}$ & $\begin{array}{l}0.18 \\
(0.01)\end{array}$ & $\begin{array}{l}0.15 \\
(0.01)\end{array}$ \\
\hline $\begin{array}{l}\text { (Parental income }-\mathrm{CZ} \text { mean) } \\
\quad * \mathrm{CZ} \text { income transmission }(\theta)\end{array}$ & $\begin{array}{c}0.64 \\
(0.16)\end{array}$ & $\begin{array}{c}0.47 \\
(0.25)\end{array}$ & $\begin{array}{c}0.61 \\
(0.27)\end{array}$ & $\begin{array}{c}0.61 \\
(0.27)\end{array}$ & $\begin{array}{c}0.38 \\
(0.14)\end{array}$ & $\begin{array}{c}0.45 \\
(0.13)\end{array}$ & $\begin{array}{l}0.76 \\
(0.16)\end{array}$ \\
\hline $\begin{array}{l}\text { SD of parental income random } \\
\text { coefficient }(\eta)\end{array}$ & $\begin{array}{c}0.006 \\
(0.018)\end{array}$ & $\begin{array}{c}0.045 \\
(0.023)\end{array}$ & $\begin{array}{c}0.052 \\
(0.026)\end{array}$ & $\begin{array}{c}0.060 \\
(0.021)\end{array}$ & $\begin{array}{c}0.020 \\
(0.015)\end{array}$ & $\begin{array}{c}0.023 \\
(0.015)\end{array}$ & $\begin{array}{c}0.015 \\
(0.015)\end{array}$ \\
\hline \multicolumn{8}{|l|}{ Across-CZ distribution: } \\
\hline $\begin{array}{l}\text { SD of CHKS income-income } \\
\text { transmission coefficient }(\theta)\end{array}$ & 0.057 & 0.057 & 0.056 & 0.056 & 0.057 & 0.057 & 0.057 \\
\hline $\begin{array}{l}\text { SD of ELS parental income- } \\
\text { child outcome transmission }\end{array}$ & 0.037 & 0.052 & 0.062 & 0.069 & 0.029 & 0.035 & 0.045 \\
\hline $\begin{array}{l}\text { Coefficient of regression of } \theta \\
\text { on ELS transmission }\end{array}$ & $\begin{array}{c}1.52 \\
(0.37)\end{array}$ & $\begin{array}{c}0.55 \\
(0.42)\end{array}$ & $\begin{array}{c}0.50 \\
(0.34)\end{array}$ & $\begin{array}{c}0.40 \\
(0.23)\end{array}$ & $\begin{array}{c}1.41 \\
(0.98)\end{array}$ & $\begin{array}{c}1.21 \\
(0.68)\end{array}$ & $\begin{array}{l}1.18 \\
(0.27)\end{array}$ \\
\hline $\mathrm{R}^{2}$ & 0.97 & 0.26 & 0.31 & 0.24 & 0.53 & 0.55 & 0.90 \\
\hline Correlation & 0.99 & 0.51 & 0.55 & 0.49 & 0.73 & 0.74 & 0.95 \\
\hline p-value, $\operatorname{SD}(\eta)=0$ (LR test) & 0.92 & 0.46 & 0.18 & 0.13 & 0.45 & 0.31 & 0.60 \\
\hline \multicolumn{8}{|l|}{ Panel B: By gender: } \\
\hline \multicolumn{8}{|l|}{ Men } \\
\hline $\begin{array}{l}\text { (Parental income }-\mathrm{CZ} \text { mean) } \\
* \mathrm{CZ} \text { income transmission }\end{array}$ & $\begin{array}{c}0.53 \\
(0.23)\end{array}$ & $\begin{array}{c}0.49 \\
(0.31)\end{array}$ & $\begin{array}{c}0.48 \\
(0.39)\end{array}$ & $\begin{array}{c}0.66 \\
(0.34)\end{array}$ & $\begin{array}{l}0.19 \\
(0.22)\end{array}$ & $\begin{array}{c}0.27 \\
(0.23)\end{array}$ & $\begin{array}{c}0.52 \\
(0.23)\end{array}$ \\
\hline $\begin{array}{l}\text { SD of ELS parental income- } \\
\text { child outcome transmission }\end{array}$ & 0.033 & 0.060 & 0.073 & 0.085 & 0.032 & 0.042 & 0.030 \\
\hline $\begin{array}{l}\text { Coefficient of regression of } \theta \\
\text { on ELS transmission }\end{array}$ & $\begin{array}{c}1.61 \\
(0.77)\end{array}$ & $\begin{array}{c}0.43 \\
(0.51)\end{array}$ & $\begin{array}{c}0.29 \\
(0.49)\end{array}$ & $\begin{array}{c}0.29 \\
(0.30)\end{array}$ & $\begin{array}{c}0.61 \\
(0.95)\end{array}$ & $\begin{array}{c}0.48 \\
(0.55)\end{array}$ & $\begin{array}{c}1.85 \\
(0.81)\end{array}$ \\
\hline $\mathrm{R}^{2}$ & 0.85 & 0.21 & 0.14 & 0.19 & 0.12 & 0.13 & 0.96 \\
\hline $\operatorname{Corr}(\theta$, ELS transmission $)$ & 0.92 & 0.46 & 0.37 & 0.44 & 0.34 & 0.36 & 0.98 \\
\hline \multicolumn{8}{|l|}{ Women } \\
\hline $\begin{array}{l}\text { (Parental income }-\mathrm{CZ} \text { mean) } \\
* \mathrm{CZ} \text { income transmission }\end{array}$ & $\begin{array}{c}0.65 \\
(0.25)\end{array}$ & $\begin{array}{c}0.35 \\
(0.31)\end{array}$ & $\begin{array}{c}0.89 \\
(0.38)\end{array}$ & $\begin{array}{c}0.73 \\
(0.39)\end{array}$ & $\begin{array}{c}0.49 \\
(0.19)\end{array}$ & $\begin{array}{c}0.54 \\
(0.17)\end{array}$ & $\begin{array}{c}0.87 \\
(0.24)\end{array}$ \\
\hline $\begin{array}{l}\text { SD of ELS parental income- } \\
\text { child outcome transmission }\end{array}$ & 0.038 & 0.020 & 0.086 & 0.096 & 0.038 & 0.037 & 0.051 \\
\hline $\begin{array}{l}\text { Coefficient of regression of } \theta \\
\text { on ELS transmission }\end{array}$ & $\begin{array}{c}1.47 \\
(0.56)\end{array}$ & $\begin{array}{c}2.85 \\
(2.53)\end{array}$ & $\begin{array}{c}0.39 \\
(0.22)\end{array}$ & $\begin{array}{c}0.25 \\
(0.16)\end{array}$ & $\begin{array}{c}1.06 \\
(0.50)\end{array}$ & $\begin{array}{l}1.24 \\
(0.44)\end{array}$ & $\begin{array}{l}1.08 \\
(0.26)\end{array}$ \\
\hline $\mathrm{R}^{2}$ & 0.96 & 0.99 & 0.34 & 0.19 & 0.51 & 0.66 & 0.94 \\
\hline $\operatorname{Corr}(\theta$, ELS transmission $)$ & 0.98 & 0.99 & 0.59 & 0.43 & 0.72 & 0.81 & 0.97 \\
\hline
\end{tabular}

Notes: All specifications are as in Table 4, column 5. All columns include main effects for CZ mean parental income and CZ income transmission and their interaction. See notes to Table 4 for details. In columns 1 and 5-7, dependent variable is a measure of child income, scaled as a percentile (0-100) of the child total family income distribution. In columns $2-4$, dependent variable is an indicator, multiplied by 100. Number of observations (rounded to the nearest 10) ranges from 11,510 to 16,200 in Panel A. 
Table 9. Decomposition of the variation in intergenerational transmission

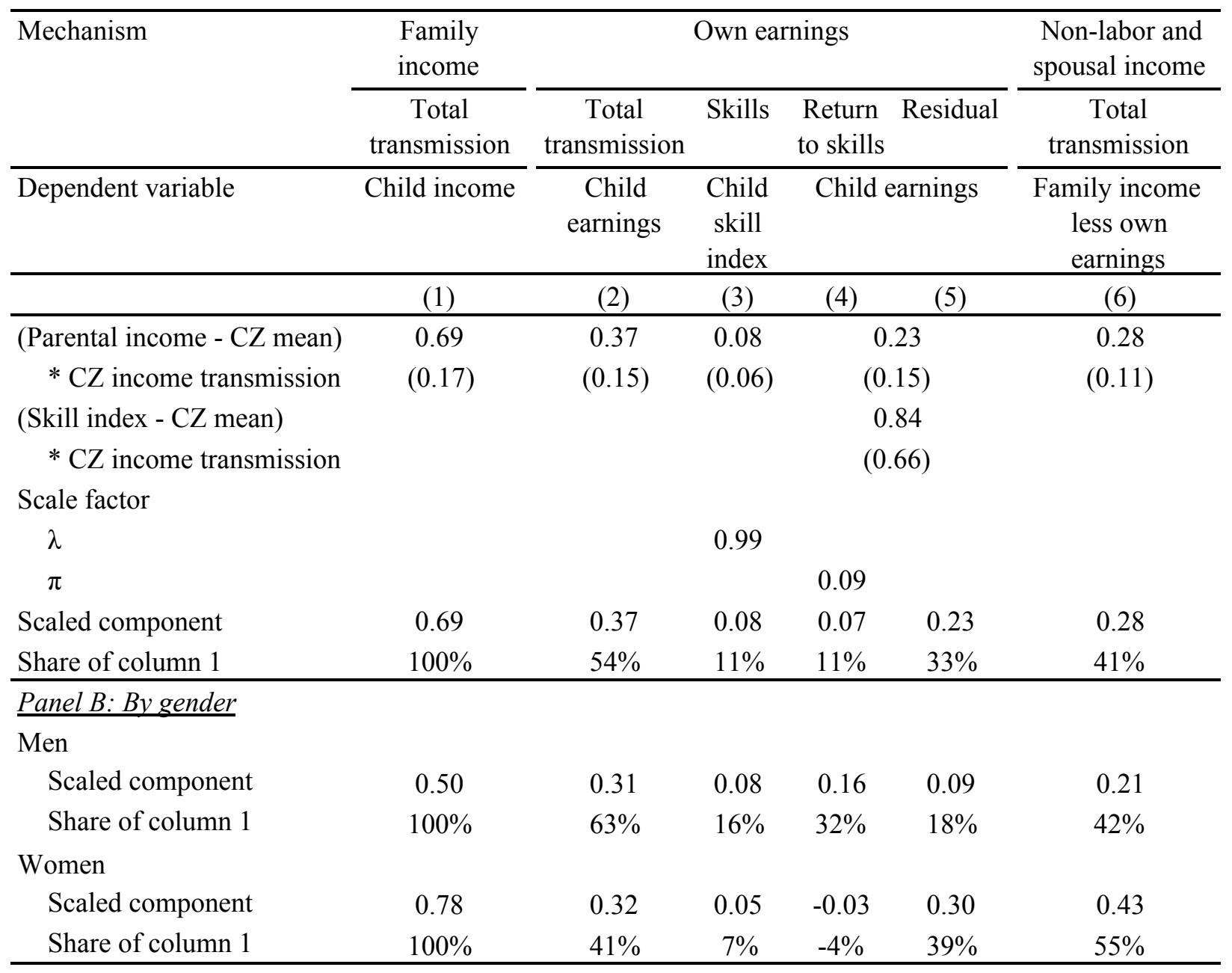

Notes: Each specification has controls for $\mathrm{CZ}$ mean parental income, the individual deviation from that mean, income transmission, and an interaction between $\mathrm{CZ}$ mean income and $\mathrm{CZ}$ income transmission. Columns 4 and 5 report a single specification, which also includes the $\mathrm{CZ}$ mean of the skill index (see notes to Table 7 for details) and its interaction with income transmission. See text for explanation of scale factors and scaling of dependent variables. 


\section{Appendices}

\section{A Additional results}

This appendix discusses additional specifications and results not included in the main tables.

\section{A.1 Descriptive statistics}

I begin with descriptive statistics for the samples used.

Appendix Table A1 presents the national relationship between parental income and child achievement, as in Table 3, column 1, for each of the achievement measures available in the ECLS, HSLS, and ELS, as well as for several summaries of educational attainment from the ELS. Parental income is less strongly related to children's test scores in the HSLS and ELS than in the ECLS, but it is not clear whether this reflects differences across grades or differences among the surveys. There is no indication of an age gradient within any individual survey.

Appendix Figure A1 presents scatterplots of mean child outcomes for each of the 13 parental income categories reported in the ELS. Parental income is scaled as a percentile, as in the main analysis, as are children's test scores, earnings, and family incomes. One of the parental income categories, zero income, is quite rare - only $0.2 \%$ of all observations so is indicated by hollow markers. For all four of the outcomes presented, the relationship with parental income is reasonably linear in these percentile plots, supporting the scaling choices adopted above. Appendix Table A7, discussed below, shows that my main results are robust to the use of several alternative scales.

\section{A.2 Additional analyses of primary specifications}

Next, I present analyses using the same interacted specifications as in the main analysis.

Appendix Figure A3 repeats the exercise from Figure 2 for other relationships. As in Figure 2, CZs are divided into deciles by $\theta_{c}$, and regressions are estimated separately for each decile. In panel A, the within-decile regression is of children's income on parental income. This is a semi-parametric version of the model from Table 8, column 1. As there, 
the coefficient across $\theta$ is quite high, and points are fairly tightly clustered around the best-fit line. Panel B repeats Figure 2, using the child's test score as the dependent variable. While there is a positive slope here, it is much attenuated, and there is a great deal more variability around the best-fit line. Panels C and D present coefficients from child income regressions that control for test scores and parental income simultaneously. The test score coefficients, in Panel C, estimate $\lambda_{c}$, while the parental income coefficients, in Panel D, estimate $\mu_{c}$. We see a steep slope in Panel C. In Panel D, the $\mu_{c}$ estimates are also more strongly correlated with $\theta_{c}$ than are the $\pi_{c}$ coefficients in panel B. This supports the conclusion in the paper that $\mu_{c}$ is a more important channel for explaining $\theta_{c}$ than is $\pi_{c}$.

Appendix Table A2 presents interacted and mixed models for the relationship between parental income and children's income in the ELS. The mixed model in column 5 repeats the results from Table 8, column 1; other columns here present simpler models without random coefficients. Across all the columns, the interaction coefficients are around 0.65 or higher, and in the random effects specifications the expected coefficient of 1 is outside of the confidence interval. CZs that CHKS estimate have higher parent-to-child income transmission also have higher transmission in the ELS, but not by quite as much. In the mixed model in column 5, the across-CZ standard deviation of income transmission is smaller than in CHKS's estimates, 0.037 vs. 0.057, but they are nearly perfectly correlated. This high correlation is not surprising, of course, since $\theta_{c}$ is defined as the return to parental income in children's income, and the $\pi_{c}$ obtained from the ELS sample differs from this only because the income measures and cohorts differ slightly. Thus, the high correlation serves to validate the use of the ELS sample for this exercise.

However, the small coefficient $\beta, 0.64$ in Column 5 and similar in earlier columns, and the correspondingly low estimated $\sigma_{\theta^{E L S}}$, remains a concern. If the ELS and tax measures were perfectly comparable, $\beta$ should equal one. The attenuated coefficient must reflect differences in the income concepts between the ELS and the tax data, either for parents or for children. A likely suspect is that the ELS children's income is measured at a younger age than in the tax data, mid-20s vs. the early 30s. This may attenuate income transmission, as 25-year-olds are often not yet settled in their careers or families. Another potential explanation is that the ELS parental income measure is from only a single year and is reported in bins, so likely 
measures parents' permanent income with error. However, when parents were asked their incomes several times in different ECLS waves, binned measures like those reported by the ELS are correlated around 0.85 across waves, and around 0.95 with a measure constructed from the three-wave average. Thus, pure measurement error relative to permanent income does not fully account for the attenuation of $\beta$. Nevertheless, it may somewhat attenuate estimates of $\theta^{E L S}$; in this case, the ELS is also likely to yield attenuated estimates of $\pi_{c}$. Any variation in the reliability of $p_{i c}$ across CZs would tend to lead me to overstate the association between $\theta_{c}$ and $\pi_{c}$.

In Table 6 , I showed that high- $\theta_{c}$ CZs have stronger relationships, on average, between parental income and children's college graduation and years of education. But I omitted from that table results for any college, the one mediator that CHKS are able to measure, due to the evident differences between the ELS version of this variable (with a sample mean of 0.84 ) and versions that can be constructed from CHKS's tax data (mean $=0.60$ ) or the ACS sample $($ mean $=0.53)$. It appears that some students with weak attachment to higher education - perhaps they enrolled briefly and dropped out, or signed up for a program at a non-accredited institution - are reporting some postsecondary enrollment in the ELS but are not captured in other surveys. Consistent with this, $70 \%$ of those with some college in the ACS have at least an associates degree, but in the ELS this share is around half.

Appendix Table A3 explores transmission to any college in the ELS, using successively more restrictive definitions of college enrollment, in the basic random effects and mixed models. In columns 1-2, I use the ELS measure without adjustment. Column 2 indicates that the transmission of parental income to child college-going is negatively correlated with CZ income transmission. This is in stark contrast to CHKS's results for income-enrollment transmission using their measure of whether tuition was paid for a student between ages 18 and 21 at an institution that made an information report to the IRS, which indicated a correlation of 0.68 with $\theta_{c}$.

Remaining columns tighten the definition of college enrollment. In columns 3-4, I count students who attended postsecondary education but did not get any certificate, degree, or other sort of credential as non-attendees; in columns 5-6 I include these students but exclude those who received only certificates; and in columns 7-8 I turn instead to an indicator for 
having an associates degree or more. Each of these specifications yields a positive (albeit weak in some cases) correlation between $\theta_{c}$ and $\pi_{c}$, suggesting that the anomalous results in columns 1-2 are driven by the students with the least meaningful connections to college. In column 8, the correlation approaches that obtained by CKHS.

\section{A.3 Alternative transmission measures}

All of the results in the main paper and in Appendix A.1 use CHKS's preferred relative mobility measure. Here, I explore three alternative measures.

Appendix Table A4 continues the exploration of transmission from parental income to children's educational attainment. Here, I repeat the mixed model specifications for each of the attainment measures from Table 6 and Appendix Table A3, but in place of CHKS's preferred measure of income transmission, I use their analogous measure of the transmission from parental income to children's college enrollment in the CZ. That is, in this table $\theta_{c}$ is the slope of an indicator for ever enrolling in college between 18 and 21 on the parents' income percentile. Not surprisingly given the discussion above, this is only weakly correlated with $\pi_{c}$ in column 1 , where the dependent variable is an indicator for any college by the age-26 ELS survey. This is a further indication that the ELS measure may be over-broad. Correlations and slopes of $\theta_{c}$ with respect to $\pi_{c}$ are much higher in the subsequent columns. Indeed, transmission from parent income to child's educational attainment in years, or to attainment of a two-year degree, is correlated 0.8 with CHKS's $\theta_{c}$ measure. Appendix Table A2 also indicated that college completion and years of education are more strongly related to parental income, at a national level, than is the ELS college enrollment measure, further indicating limitations of the latter.

Appendix Table A5 returns to the income transmission concept for $\theta_{c}$, but explores two alternative measures. One, labeled "later," is the measure computed by CHKS for the younger, 1983-5 birth cohorts, with adult incomes measured at younger ages. The second, "causal" measure is constructed by Chetty and Hendren (forthcoming) based on families that move from one CZ to another. Three dependent variables are considered: Children's adult family income (in percentiles, 0-100), children's 12th grade math scores (also in percentiles), and the child's years of completed education as of age 26 (multiplied by 100). Results 
are generally similar across mobility measures; if anything, the alternative measures yield weaker relationships with ELS transmission from parental income to children's achievement and attainment.

\section{A.4 Robustness to scaling and additional controls}

CHKS's $\theta_{c}$ is strongly correlated with CZ-level racial composition, raising the possibility that what appears to be variation in the transmission of parental income is in fact due to differences in the omitted variable bias due to differences in the correlation of race with parental income. Appendix Table A6 considers the same three outcomes considered earlier along with the baseline CHKS mobility measure for the 1980-2 cohorts, but adds to this base specification indicators for the child's race and gender and, in columns 3, 6, and 9, interactions of these with the income transmission measure. I do not present results for the forward regression here, as with controls equation (7) is not valid. There is some evidence here that race is an important factor - the standard deviation of income transmission implied by the ELS data falls from 0.038 without controls to 0.023 when race is controlled and allowed to interact with $\theta_{c}$. However, the general conclusions that income transmission is positively but weakly correlated with test score transmission, and somewhat more strongly correlated with attainment transmission, are robust to the additional controls. There is no indication that the omission of race leads me to substantially overstate the mediating role of human capital.

Appendix Table A7 explores the sensitivity of my main test score transmission results to different scaling choices. In column 2, I use the child's test score in standard deviations, rather than in percentiles. Column 3 rescales the test score in terms of the predicted earnings associated with that score, as in Bond and Lang (forthcoming). Columns 4 and 5 return to using the test score percentile but rescale parental income, using first the log of parental income and then a predicted test score percentile given parental income. While the scale of the coefficients varies across these columns, the general pattern that $\pi_{c}$ is correlated around 0.3 with $\theta_{c}$ is robust to each of the alternative scalings. 


\section{A.5 Loosening the normality assumption}

Most of my analysis is based on a mixed model, equation (12). I estimate this model by maximum likelihood, under the assumption that $\alpha_{c}$ and $\eta_{c}$ are jointly normal, that $\epsilon_{i c}$ is also normal and independent of the former two, and that all three are orthogonal to $\bar{p}_{c}, p_{i c}-\bar{p}_{c}$, $\theta_{c}$, and the interactions $\bar{p}_{c} \theta_{c}$ and $\left(p_{i c}-\bar{p}_{c}\right) \theta_{c}$. The normality restrictions are unattractive, however.

In this appendix, I present an alternative, two-step estimator that does not rely on normality. Unfortunately, it is very poorly behaved in the ELS sample.

Specifically, I estimate separate regressions of children's test scores on parental income in each CZ. Samples are quite small - the median CZ has 85 observations, but $10 \%$ of CZs have fewer than 20 observations. I discard CZs with 10 or fewer observations, the 1st percentile of the sample. For all other CZs, I estimate $\hat{\pi}_{c}$ and its associated standard error. In computing the standard errors, I pool data from all CZs to estimate $\sigma_{\epsilon}^{2}$, the residual variance; I do not take account of the multi-stage nature of the sample, which almost certainly leads me to understate the sampling error in $\hat{\pi}_{c}$.

Appendix Figure A2 plots the $\hat{\pi}_{c}$ estimates and their confidence intervals against $\theta_{c}$. While there is a correlation, it is difficult to see in the graph, as the individual $\hat{\pi}_{c}$ estimates are extremely noisy. A regression of $\hat{\pi}_{c}$ on $\theta_{c}$ yields coefficient $\beta=0.13$, notably smaller than seen earlier but highly significant. The residual from this regression is $\hat{\eta}_{c}$. It equals $\eta_{c}$ plus a sampling error component, the distribution of which is estimated by the standard error of $\hat{\pi}_{c}$. To estimate $\sigma_{\eta}^{2}$, then, I compute the variance across CZs of $\hat{\eta}_{c}$ and subtract the component implied by the estimated standard errors:

$$
\hat{\sigma}_{\eta}^{2}=\frac{1}{J-1} \sum_{c=1}^{J} \hat{\eta}_{c}^{2}-\frac{1}{J} \sum_{c=1}^{J} \hat{V}\left(\hat{\pi}_{c}\right) .
$$

In practice, this is negative - the average of (conservatively estimated) sampling variances is larger than the total variance of the coefficients (after removing the component explained by $\theta_{c}$ ). I interpret this as an indication that the available sample is too small to support this sort of exercise - the noise in the estimated sampling variances is too large relative 
to the signal we are attempting to extract from the estimated coefficients. The exercise can perhaps be interpreted as evidence that normality assumptions are not leading me to understate $\beta$. However, for the full variance decomposition and estimation of the forward regression (7), there is no alternative for my purposes to the normality assumption imposed in the main text.

\section{A.6 Non-cognitive skills}

Finally, Appendix Table A8 presents an analysis of children's non-cognitive skills. These are drawn from batteries included in the the ELS 10th grade survey (panel A), the ECLS 5th grade student survey (panel B), and the ECLS 5th grade teacher survey (panel C). The specific measures are:

ELS 10th grade survey. Each of the measures used is created by principal factor analysis from student responses to questions of the form "How often do these things apply to you?", with response options "almost never," "sometimes," "often," and "almost always." Quotations are from National Center for Education Statistics (undated).

Instrumental motivation. Intended to capture "motivation to perform well academically in order to satisfy external goals like future job opportunities or financial security." Based on three responses about whether the student studies in order to achieve long-run success.

General effort and persistence. Based on five questions characterizing effort put into studying.

General control beliefs. Intended to capture "expectations of success in academic learning." Based on four responses characterizing the student's self-perceived ability to achieve desired academic outcomes.

Self efficacy, math. Based on five responses characterizing the student's self-perceived ability to succeed in math classes and his/her views about the importance of innate ability in math.

Self efficacy, reading. Based on five responses characterizing the student's self-perceived ability to succeed in reading classes.

ECLS 5th grade student survey. Students rated 42 statements about their perceptions of themselves as "not at all true," "a little bit true," "mostly true," and "very true." These were averaged into several scales. Quotations are from Tourangeau et al. (2006). 
Perceived interest / competence in reading. Eight statements concerning "reading grades, the difficulty of reading work, and [the student's] interest in and enjoyment of reading."

Perceived interest / competence in math. Eight statements concerning "mathematics grades, the difficulty of mathematics work, and [the student's] interest in and enjoyment of mathematics."

Perceived interest / competence in all school subjects. Six statements concerning "how well [the student] do[es] in 'all school subjects' and [the student's] enjoyment of 'all school subjects."'

Perceived interest / competence in peer relations. Six statements concerning "how easily [the student] make[s] friends and get[s] along with children as well as their perception of their popularity."

Externalizing problem behaviors. Six statements concerning "externalizing problem behaviors such as fighting and arguing 'with other kids,' talking and disturbing others, and problems with distractibility."

Internalizing problem behaviors. Eight statements concerning "internalizing problem behaviors such as feeling 'sad a lot of the time,' feeling lonely, feeling ashamed of mistakes, feeling frustrated, and worrying about school and friendships."

ECLS 5th grade teacher survey. Teachers rated 26 statements about how often students exhibited certain social skills and behaviors as "never," "sometimes," "often," and "very often." These were averaged into several scales. Quotations are from Tourangeau et al. (2006).

Approaches to learning. "Measures behaviors that affect the ease with which children can benefit from the learning environment." Based on seven items relating to "the child's attentiveness, tax persistence, eagerness to learn, learning independence flexibility, [] organization ... [and] child follows classroom rules."

Self control. "Four items that indicate the child's ability to control behavior by respecting the property rights of others, controlling temper, accepting peer ideas for group activities, and responding appropriately to pressure from peers."

Interpersonal skills. "Five items that rate the child's skill in forming and maintaining friendships; getting along with people who are different; comforting or helping other children; expressing feelings, ideas, and opinions in positive ways; and showing sensitivity to the feelings of others."

Peer relations. This is a combination of the self-control and interpersonal scales.

Externalizing problem behaviors. This scale "includes acting out behaviors": six items "rate the frequency with which a child argues, fights, gets angry, acts impulsively, [] disturbs ongoing activities ... [and] talks during quiet study time."

Internalizing problem behaviors. Four items ask about "the apparent presence of anxiety, loneliness, low self-esteem, and sadness." 
For all of the non-cognitive items, I reverse-code so that higher values are better, then convert to percentiles. I also present results for an overall non-cognitive skill index from each survey. To form this, I convert each listed scale to a z-score, average them, then convert the average to percentiles.

Results are mixed. The $\beta$ coefficient on the parental income - CZ income transmission interaction is generally small and not statistically significant, and frequently has the wrong sign. For about half of the measures, there is statistically significant variation across CZs in the return to parental income (i.e., $\sigma_{\eta} \neq 0$ ). Overall, there is little indication that non-cognitive skills are important mediators of income-to-income transmission. The ECLS teacher survey results, however, tell a different story, with strong associations with income transmission. This is not due to the use of different measures in the child and teacher surveys - even when the concepts overlap (e.g., for externalizing problem behaviors), results are quite different. It is not clear how to account for this discrepancy. It may indicate that teachers in high-transmission CZs tend to be more biased in their assessments of low-income children, but this is quite speculative. 
Appendix Figure A1. Mean child outcomes by parental income, ELS

A. Child family income percentile

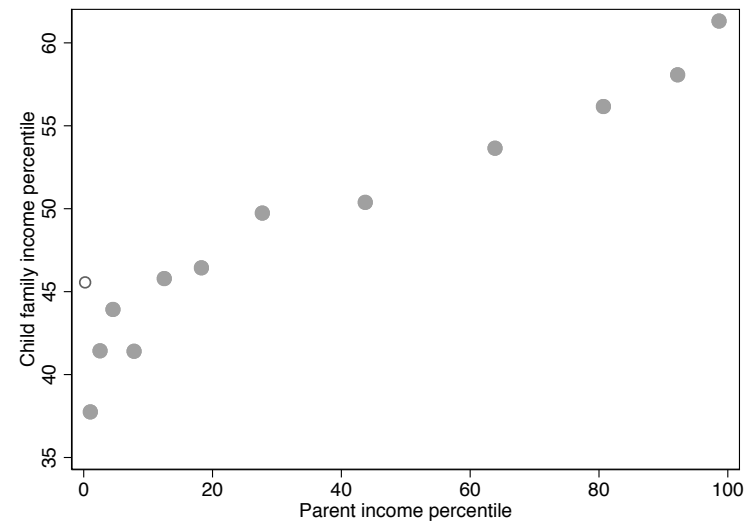

C. $12^{\text {th }}$ grade math score percentile

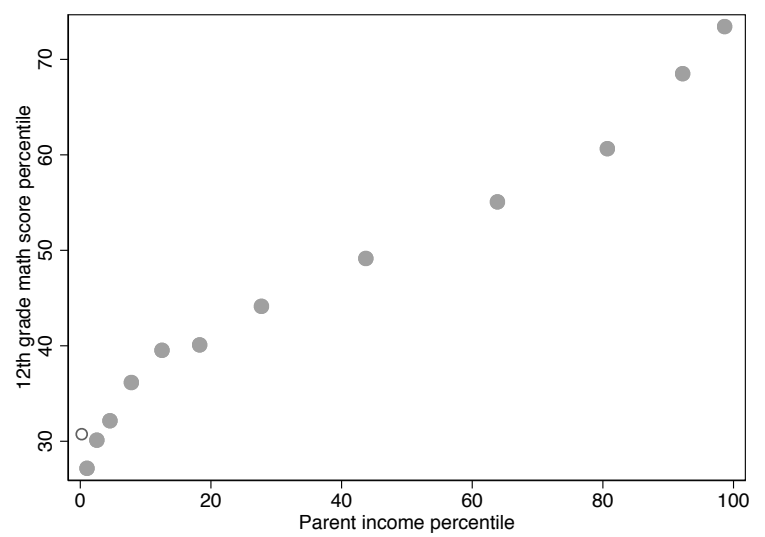

B. Child earnings percentile

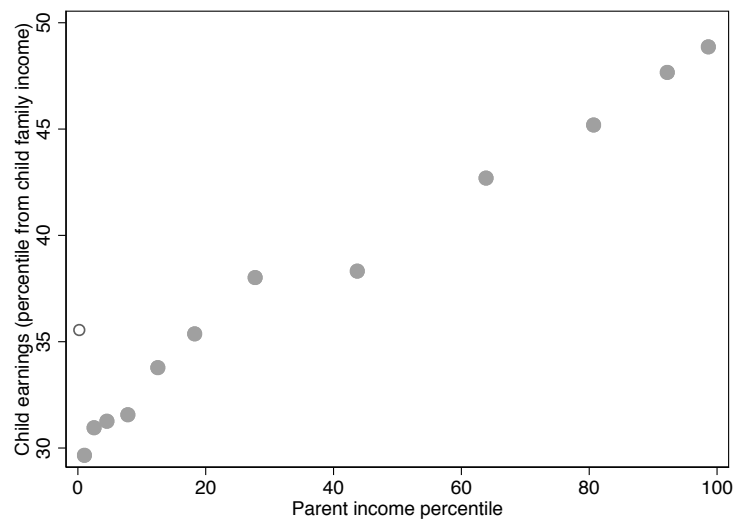

D. Years of education at age 26

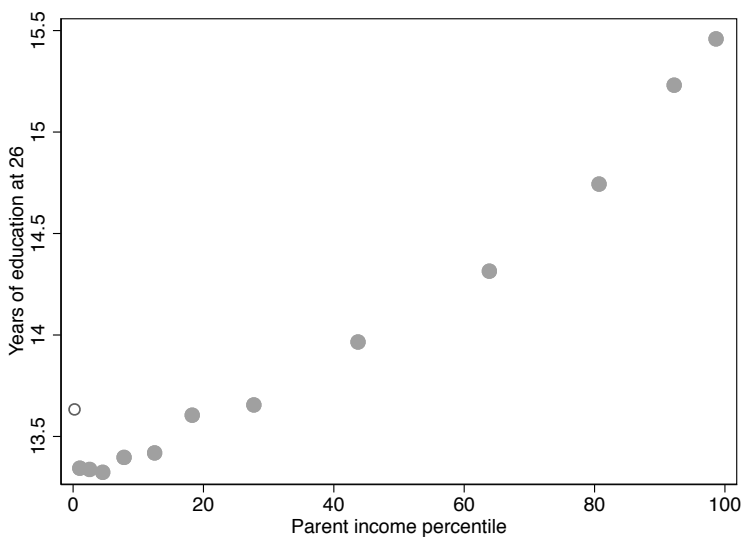

Notes: Each point represents a single categorical response to the ELS parental income question, assigned to the midpoint of the percentile range covered by that category. Y-axis plots means of the indicated child outcome for each category. The hollow points represent the $0.2 \%$ of observations reporting zero parental income. Child family incomes, earnings, and $12^{\text {th }}$ grade math scores are measured as percentiles of the national distributions. 
Appendix Figure A2. CZ-level estimates of parental income - child test score transmission

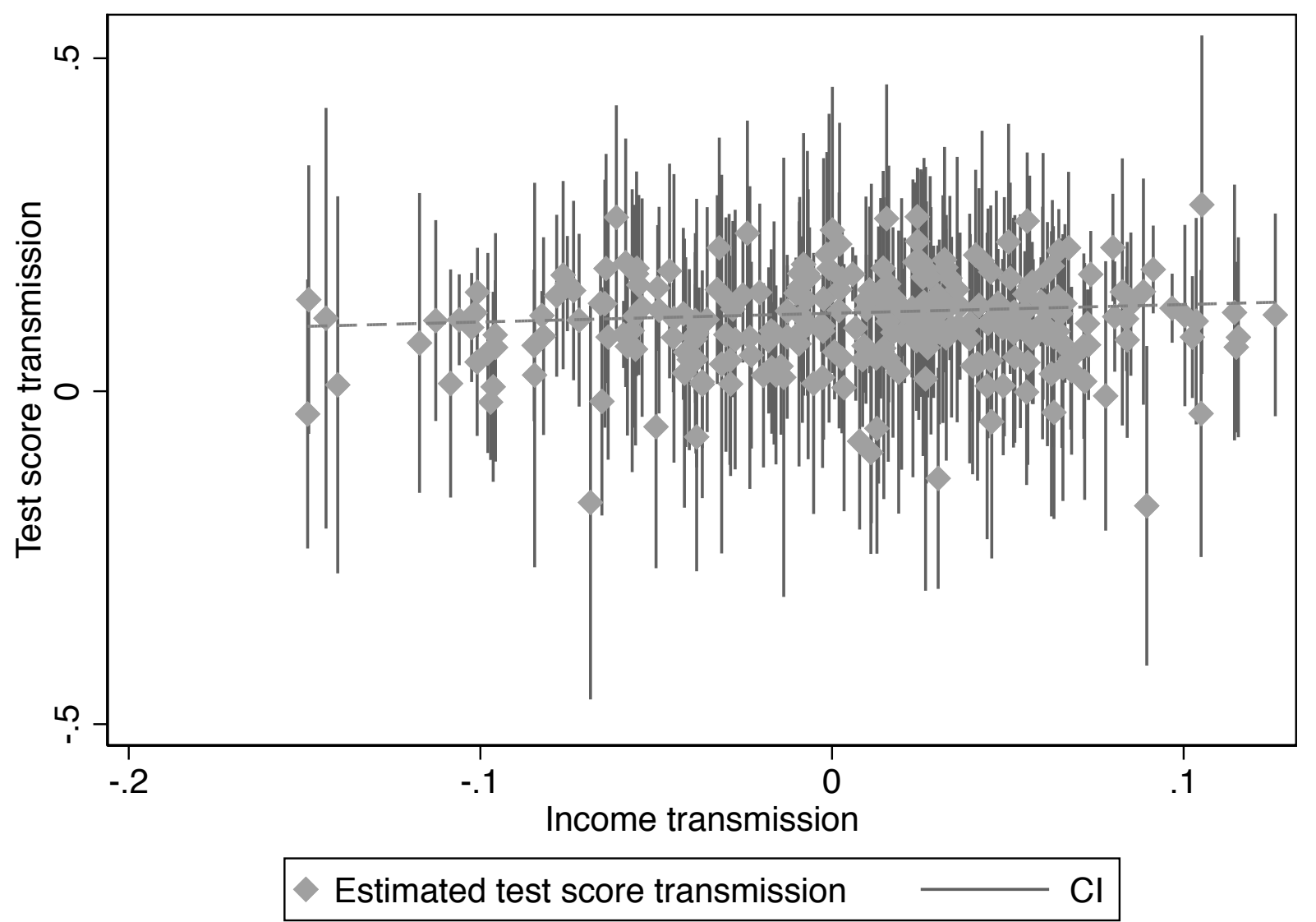

Notes: Points represent individual CZs. The x-axis plots the CZ's income transmission, as measured by CHKS. The y-axis represents the coefficient of a regression of the child's test score percentile on the parents' income percentile, estimated using data from a single CZ. Vertical spikes show $95 \%$ confidence intervals. Dashed line represents a regression of the $\mathrm{CZ}$ test score transmission coefficient on $\mathrm{CZ}$ income transmission, weighted by the inverse sampling variance of the former. 
Appendix Figure A3. Parental income to child outcome transmission, by CZ income transmission $(\theta)$ decile

A. Income transmission

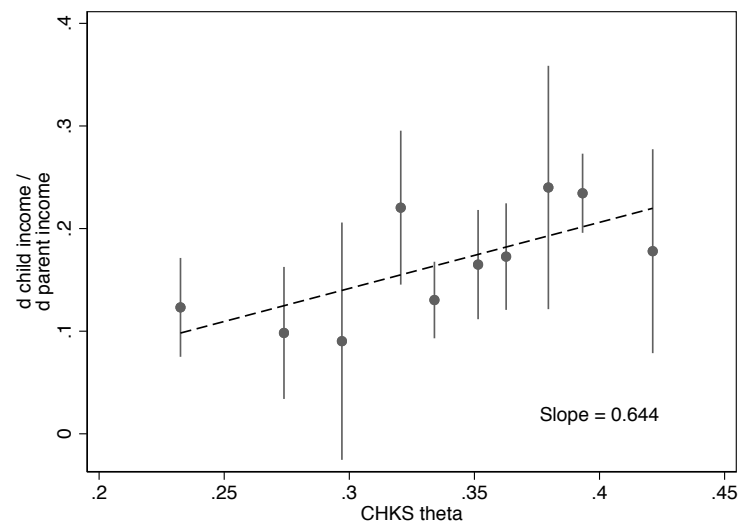

C. Children's test scores and incomes

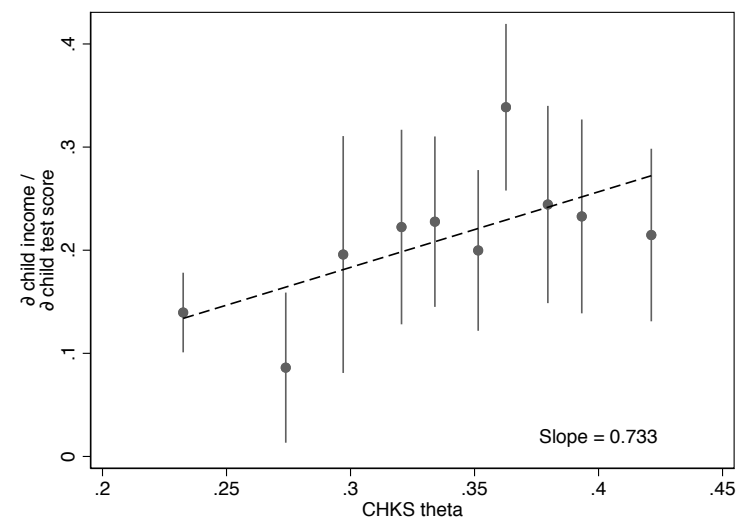

B. Test score transmission

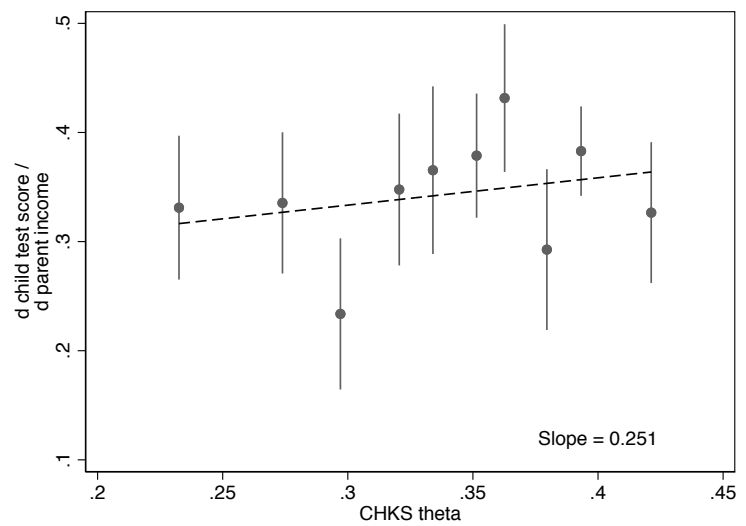

D. Income transmission | test scores

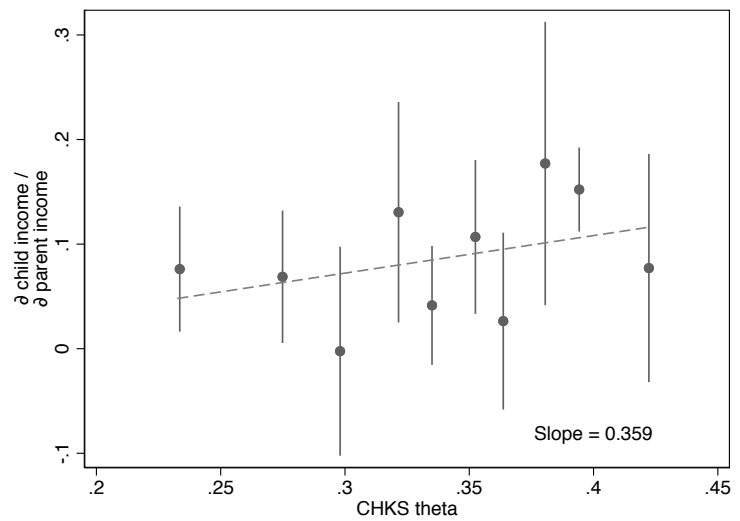

Notes: CZs are divided into deciles based on CHKS's income transmission (relative mobility) measure. Figure plots coefficients and 95\% confidence intervals for regressions estimated separately for each decile. In Panel A, the regression is of the child's income percentile $(y)$ on the parent's income percentile $(p)$. In Panel $\mathrm{B}$, it is of the child's test score percentile $(s)$ on $p$, as in Figure 2. In Panels C and D, $y$ is regressed on $s$ and $p$; Panel $\mathrm{C}$ shows the $s$ coefficients and Panel $\mathrm{D}$ shows the $p$ coefficients. Each regression includes CZ fixed effects and uses ELS sampling weights. Dashed lines show unweighted regressions of the decile coefficients on the decile mean income transmission; their slopes are shown in the lower right of each panel. 
Appendix Table A1. Transmission from parental income to children's outcomes at the national level, by sample, grade, and subject

\begin{tabular}{|c|c|c|c|c|c|c|}
\hline & \multicolumn{2}{|c|}{ Math } & \multicolumn{2}{|c|}{ Reading } & \multicolumn{2}{|c|}{ Other } \\
\hline & Coefficient & $\mathrm{N}$ & Coefficient & $\mathrm{N}$ & Coefficient & $\mathrm{N}$ \\
\hline & $(1)$ & $(2)$ & (3) & $(4)$ & $(5)$ & $(6)$ \\
\hline \multicolumn{7}{|l|}{ ECLS-K } \\
\hline K (spring) & $\begin{array}{c}0.40 \\
(0.01)\end{array}$ & 19,190 & $\begin{array}{c}0.36 \\
(0.01)\end{array}$ & 18,500 & & \\
\hline G1 (spring) & $\begin{array}{c}0.41 \\
(0.01)\end{array}$ & 16,370 & $\begin{array}{c}0.37 \\
(0.01)\end{array}$ & 16,080 & & \\
\hline G3 & $\begin{array}{c}0.42 \\
(0.01)\end{array}$ & 14,180 & $\begin{array}{c}0.43 \\
(0.01)\end{array}$ & 14,090 & & \\
\hline G5 & $\begin{array}{c}0.43 \\
(0.02)\end{array}$ & 11,140 & $\begin{array}{c}0.43 \\
(0.02)\end{array}$ & 11,130 & & \\
\hline G8 & $\begin{array}{c}0.42 \\
(0.02)\end{array}$ & 9,210 & $\begin{array}{c}0.44 \\
(0.02)\end{array}$ & 9,150 & & \\
\hline \multicolumn{7}{|l|}{ HSLS } \\
\hline G9 & $\begin{array}{c}0.32 \\
(0.01)\end{array}$ & 20,170 & & & & \\
\hline G11 & $\begin{array}{c}0.31 \\
(0.01)\end{array}$ & 20,460 & & & & \\
\hline \multicolumn{7}{|l|}{ ELS } \\
\hline G10 & $\begin{array}{c}0.34 \\
(0.01)\end{array}$ & 15,240 & $\begin{array}{c}0.32 \\
(0.01)\end{array}$ & 15,240 & & \\
\hline G12 & $\begin{array}{c}0.35 \\
(0.01)\end{array}$ & 13,650 & & & & \\
\hline Any college $(* 100)$ & & & & & $\begin{array}{c}0.24 \\
(0.01)\end{array}$ & 13,250 \\
\hline \multicolumn{3}{|c|}{ College completion $(* 100)$} & & & $\begin{array}{c}0.45 \\
(0.02)\end{array}$ & 13,250 \\
\hline \multicolumn{3}{|c|}{ Years of education $(* 100)$} & & & $\begin{array}{c}1.87 \\
(0.07)\end{array}$ & 13,250 \\
\hline Income at 26 & & & & & $\begin{array}{c}0.16 \\
(0.01) \\
\end{array}$ & 11,510 \\
\hline
\end{tabular}

Notes: Each entry represents the coefficient from a separate weighted least squares regression of the child's outcome on family income, with commuting zone fixed effects. Parental incomes, test scores, and child incomes are measured in percentile units, scaled 0-100. Any college and college completion are binary, but scaled as 0/100 for readability; years of education is multiplied by 100 for the same reason. Sample sizes are rounded to the nearest 10 . 
Appendix Table A2. Income transmission in the ELS

\begin{tabular}{|c|c|c|c|c|c|}
\hline & $(1)$ & $(2)$ & (3) & $(4)$ & $(5)$ \\
\hline \multirow[t]{2}{*}{ Parental income - CZ mean } & 0.16 & 0.16 & 0.17 & 0.16 & 0.17 \\
\hline & $(0.01)$ & $(0.01)$ & $(0.01)$ & $(0.01)$ & $(0.01)$ \\
\hline \multirow[t]{2}{*}{$\mathrm{CZ}$ mean parental income } & 0.32 & 0.33 & 0.34 & & 0.34 \\
\hline & $(0.04)$ & $(0.04)$ & $(0.04)$ & & $(0.04)$ \\
\hline \multirow[t]{2}{*}{$\mathrm{CZ}$ income transmission $(\theta)$} & & -62.7 & -65.2 & & -76.5 \\
\hline & & $(32.9)$ & $(29.8)$ & & $(30.9)$ \\
\hline (Parental income - CZ mean) & & 0.71 & 0.63 & 0.64 & 0.64 \\
\hline * $\mathrm{CZ}$ income transmission $(\theta)$ & & $(0.20)$ & $(0.16)$ & $(0.20)$ & $(0.16)$ \\
\hline $\mathrm{CZ}$ mean parental income & & 1.08 & 1.27 & & 1.34 \\
\hline * $\mathrm{CZ}$ income transmission $(\theta)$ & & $(0.66)$ & $(0.57)$ & & $(0.61)$ \\
\hline \multirow[t]{2}{*}{ SD of parental income random coefficient $(\eta)$} & & & & & 0.006 \\
\hline & & & & & $(0.018)$ \\
\hline CZ effects & None & None & $\mathrm{RE}$ & $\mathrm{FE}$ & $\mathrm{RE}$ \\
\hline \multicolumn{6}{|l|}{ Across-CZ distribution: } \\
\hline $\mathrm{SD}$ of CHKS CZ income transmission $\left(\theta^{\mathrm{CHKS}}\right)$ & & 0.057 & 0.057 & 0.057 & 0.057 \\
\hline SD of ELS income transmission $\left(\theta^{\mathrm{ELS}}\right)$ & & 0.040 & 0.036 & 0.036 & 0.037 \\
\hline \multirow[t]{2}{*}{ Coefficient of between- $\mathrm{CZ}$ regression of $\theta^{\mathrm{CHKS}}$ on $\theta^{\mathrm{ELS}}$} & & & & & 1.52 \\
\hline & & & & & $(0.37)$ \\
\hline $\mathrm{R}^{2}$ & & & & & 0.97 \\
\hline $\operatorname{Corr}\left(\theta^{\mathrm{CHKS}}, \theta^{\mathrm{ELS}}\right)$ & & 1 & 1 & 1 & 0.99 \\
\hline p-value, $\operatorname{SD}(\eta)=0 / \operatorname{corr}\left(\theta^{\mathrm{CHKS}}, \theta^{\mathrm{ELS}}\right)=1$ (LR test $)$ & & & & & 0.92 \\
\hline
\end{tabular}

Notes: Dependent variable in each column is the child's family income at age 26, in percentile units (0-100). Specifications are otherwise identical to those in Table 4; see notes to that table for details. Number of observations (rounded to the nearest 10) $=11,510$. 
Appendix Table A3. Parental income and children's educational attainment in the ELS

\begin{tabular}{|c|c|c|c|c|c|c|c|c|}
\hline & \multicolumn{2}{|c|}{$\begin{array}{c}\text { Any college } \\
(0 / 100)\end{array}$} & \multicolumn{2}{|c|}{$\begin{array}{l}\text { Exclude those } \\
\text { with no } \\
\text { credentials at } \\
\text { all } \\
\end{array}$} & \multicolumn{2}{|c|}{$\begin{array}{c}\text { Exclude } \\
\text { certificates }\end{array}$} & \multicolumn{2}{|c|}{$\begin{array}{c}2 \text { year degree } \\
\text { or more }\end{array}$} \\
\hline & $(1)$ & $(2)$ & $(3)$ & $(4)$ & $(5)$ & $(6)$ & $(7)$ & $(8)$ \\
\hline \multirow[t]{2}{*}{ Parental income - CZ mean } & 0.22 & 0.24 & 0.37 & 0.38 & 0.28 & 0.30 & 0.44 & 0.44 \\
\hline & $(0.01)$ & $(0.01)$ & $(0.02)$ & $(0.02)$ & $(0.01)$ & $(0.01)$ & $(0.02)$ & $(0.01)$ \\
\hline \multirow[t]{2}{*}{$\mathrm{CZ}$ mean parental income } & 0.49 & 0.48 & 0.78 & 0.79 & 0.69 & 0.70 & 0.98 & 0.99 \\
\hline & $(0.05)$ & $(0.04)$ & $(0.07)$ & $(0.07)$ & $(0.06)$ & $(0.05)$ & $(0.07)$ & $(0.06)$ \\
\hline \multirow[t]{2}{*}{$\mathrm{CZ}$ income transmission $(\theta)$} & -52 & -51 & -64 & -67 & -59 & -59 & -70 & -68 \\
\hline & $(47)$ & $(41)$ & (69) & $(66)$ & $(46)$ & $(42)$ & $(61)$ & $(60)$ \\
\hline (Parental income - $\mathrm{CZ}$ mean) & -0.11 & -0.20 & 0.37 & 0.32 & 0.12 & 0.08 & 0.60 & 0.56 \\
\hline * $\mathrm{CZ}$ income transmission $(\theta)$ & $(0.20)$ & $(0.21)$ & $(0.29)$ & $(0.27)$ & $(0.22)$ & $(0.23)$ & $(0.31)$ & $(0.27)$ \\
\hline $\mathrm{CZ}$ mean parental income & 0.97 & 0.93 & 1.42 & 1.42 & 1.02 & 1.01 & 1.42 & 1.41 \\
\hline * $\mathrm{CZ}$ income transmission $(\theta)$ & $(0.91)$ & $(0.78)$ & $(1.37)$ & $(1.29)$ & $(0.90)$ & $(0.80)$ & $(1.20)$ & $(1.18)$ \\
\hline \multirow[t]{2}{*}{ SD of parental income random coefficient $(\eta)$} & & 0.10 & & 0.07 & & 0.09 & & 0.05 \\
\hline & & $(0.02)$ & & $(0.02)$ & & $(0.01)$ & & $(0.02)$ \\
\hline \multicolumn{9}{|l|}{ Across-CZ distribution: } \\
\hline SD of CZ income transmission $(\theta)$ & 0.06 & 0.06 & 0.06 & 0.06 & 0.06 & 0.06 & 0.06 & 0.06 \\
\hline SD of p-attainment transmission $(\pi)$ & $<0$ & 0.10 & 0.02 & 0.07 & 0.01 & 0.09 & 0.03 & 0.06 \\
\hline \multirow[t]{2}{*}{ Coefficient of regression of $\theta$ on $\pi$} & & -0.06 & & 0.22 & & 0.04 & & 0.51 \\
\hline & & $(0.06)$ & & $(0.18)$ & & $(0.10)$ & & $(0.29)$ \\
\hline $\mathrm{R}^{2}$ & & 0.01 & & 0.07 & & 0.00 & & 0.29 \\
\hline $\operatorname{Corr}(\theta, \pi)$ & 1 & -0.11 & 1 & 0.27 & 1 & 0.05 & 1 & 0.54 \\
\hline p-value, $\operatorname{SD}(\eta)=0 / \operatorname{corr}(\theta, \pi)=1($ LR test $)$ & & $<0.01$ & & $<0.01$ & & $<0.01$ & & 0.04 \\
\hline
\end{tabular}

Notes: Specifications are as in Table 4, columns 3 (odd numbered columns here) and 5 (even numbered columns). See notes to that table for details. Dependent variables are scaled as 0 for failures and 100 for successes. Columns 3-8 recode some successes from columns 1-2 as failures, but are otherwise identical. Number of observations (rounded to the nearest 10) $=13,250$. 
Appendix Table A4. Models using CHKS's measure of CZ-level transmission of parental income to children's college enrollment

\begin{tabular}{|c|c|c|c|c|c|c|}
\hline & $\begin{array}{c}\text { Any } \\
\text { college } \\
(0 / 100)\end{array}$ & $\begin{array}{c}\text { College } \\
\text { graduate } \\
(0 / 100)\end{array}$ & $\begin{array}{c}\text { Years of } \\
\text { education } \\
(* 100)\end{array}$ & $\begin{array}{c}\text { Any } \\
\text { college } \\
\text { credential } \\
(0 / 100) \\
\end{array}$ & $\begin{array}{c}\text { Any college } \\
\text { exc. UG } \\
\text { certificates } \\
(0 / 100) \\
\end{array}$ & $\begin{array}{c}2 \text { year } \\
\text { degree } \\
\text { or more } \\
(0 / 100) \\
\end{array}$ \\
\hline & $(1)$ & (2) & (3) & (4) & (5) & $(6)$ \\
\hline Parental income - $\mathrm{CZ}$ mean & $\begin{array}{c}0.23 \\
(0.01)\end{array}$ & $\begin{array}{c}0.45 \\
(0.02)\end{array}$ & $\begin{array}{c}1.85 \\
(0.06)\end{array}$ & $\begin{array}{c}0.38 \\
(0.02)\end{array}$ & $\begin{array}{c}0.29 \\
(0.01)\end{array}$ & $\begin{array}{c}0.44 \\
(0.01)\end{array}$ \\
\hline $\mathrm{CZ}$ mean parental income & $\begin{array}{c}0.46 \\
(0.04)\end{array}$ & $\begin{array}{c}0.97 \\
(0.06)\end{array}$ & $\begin{array}{c}3.97 \\
(0.25)\end{array}$ & $\begin{array}{c}0.76 \\
(0.06)\end{array}$ & $\begin{array}{c}0.69 \\
(0.05)\end{array}$ & $\begin{array}{c}0.97 \\
(0.06)\end{array}$ \\
\hline $\begin{array}{l}\text { CZ transmission of parental income to } \\
\text { children's college enrollment }(\theta)\end{array}$ & $\begin{array}{l}-71 \\
(28)\end{array}$ & $\begin{array}{l}-105 \\
(39)\end{array}$ & $\begin{array}{l}-461 \\
(146)\end{array}$ & $\begin{array}{l}-132 \\
(32)\end{array}$ & $\begin{array}{l}-52 \\
(34)\end{array}$ & $\begin{array}{l}-111 \\
(35)\end{array}$ \\
\hline $\begin{array}{l}\text { (Parental income - } \mathrm{CZ} \text { mean) } \\
\quad * \mathrm{CZ} \text { income-enrollment transmission }(\theta)\end{array}$ & $\begin{array}{c}0.29 \\
(0.13)\end{array}$ & $\begin{array}{c}0.66 \\
(0.18)\end{array}$ & $\begin{array}{c}2.84 \\
(0.70)\end{array}$ & $\begin{array}{c}0.57 \\
(0.18)\end{array}$ & $\begin{array}{c}0.36 \\
(0.14)\end{array}$ & $\begin{array}{c}0.63 \\
(0.17)\end{array}$ \\
\hline $\begin{array}{l}\mathrm{CZ} \text { mean parental income } \\
\quad * \mathrm{CZ} \text { income-enrollment transmission }(\theta)\end{array}$ & $\begin{array}{c}1.10 \\
(0.53)\end{array}$ & $\begin{array}{c}2.09 \\
(0.79)\end{array}$ & $\begin{array}{c}9.13 \\
(2.93)\end{array}$ & $\begin{array}{c}2.35 \\
(0.64)\end{array}$ & $\begin{array}{c}0.81 \\
(0.65)\end{array}$ & $\begin{array}{c}2.05 \\
(0.70)\end{array}$ \\
\hline SD of parental income random coefficient $(\eta)$ & $\begin{array}{c}0.10 \\
(0.01)\end{array}$ & $\begin{array}{c}0.07 \\
(0.03)\end{array}$ & $\begin{array}{c}0.19 \\
(0.12)\end{array}$ & $\begin{array}{c}0.05 \\
(0.02)\end{array}$ & $\begin{array}{c}0.08 \\
(0.01)\end{array}$ & $\begin{array}{c}0.04 \\
(0.02)\end{array}$ \\
\hline \multicolumn{7}{|l|}{ Across-CZ distribution: } \\
\hline SD of CHKS enrollment transmission $(\theta)$ & 0.09 & 0.09 & 0.09 & 0.09 & 0.09 & 0.09 \\
\hline SD of p-attainment transmission $(\pi)$ & 0.10 & 0.09 & 0.31 & 0.07 & 0.08 & 0.07 \\
\hline Coefficient of regression of $\theta$ on $\pi$ & $\begin{array}{c}0.22 \\
(0.10)\end{array}$ & $\begin{array}{c}0.59 \\
(0.26)\end{array}$ & $\begin{array}{c}0.22 \\
(0.10)\end{array}$ & $\begin{array}{c}0.80 \\
(0.25)\end{array}$ & $\begin{array}{c}0.38 \\
(0.15)\end{array}$ & $\begin{array}{c}1.02 \\
(0.34)\end{array}$ \\
\hline $\mathrm{R}^{2}$ & 0.06 & 0.39 & 0.63 & 0.45 & 0.14 & 0.64 \\
\hline $\operatorname{Corr}(\theta, \pi)$ & 0.25 & 0.62 & 0.80 & 0.67 & 0.37 & 0.80 \\
\hline p-value, $\operatorname{SD}(\eta)=0 / \operatorname{corr}(\theta, \pi)=1($ LR test $)$ & $<0.01$ & 0.21 & 0.60 & 0.03 & $<0.01$ & 0.10 \\
\hline
\end{tabular}

Notes: Specifications are as in Table 4, column 5, but use a different CZ-level transmission measure for $\theta$. See notes to Table 4 for details. Dependent variables in columns 1-2 and 4-6 are scaled as 0 for failures and 100 for successes; in column 3, dependent variable is years of education multiplied by 100 . Number of observations (rounded to the nearest 10) $=13,250$. 
Appendix Table A5. Alternative income transmission measures

\begin{tabular}{|c|c|c|c|c|c|c|c|c|c|}
\hline \multirow{2}{*}{$\begin{array}{l}\text { Outcome } \\
\text { Transmission measure } \\
\end{array}$} & \multicolumn{3}{|c|}{$\begin{array}{l}\text { Child family income } \\
\text { (percentile) }\end{array}$} & \multicolumn{3}{|c|}{$\begin{array}{l}\text { 12th grade math score } \\
\text { (percentile) }\end{array}$} & \multicolumn{3}{|c|}{$\begin{array}{c}\text { Educational } \\
\text { attainment } \\
\text { (years*100) } \\
\end{array}$} \\
\hline & Base & Later & Causal & Base & Later & Causal & Base & Later & Causal \\
\hline & $(1)$ & $(2)$ & (3) & (4) & $(5)$ & $(6)$ & $(7)$ & $(8)$ & (9) \\
\hline \multirow[t]{2}{*}{ Parental income - CZ mean } & 0.17 & 0.17 & 0.17 & 0.33 & 0.33 & 0.33 & 1.86 & 1.86 & 1.87 \\
\hline & $(0.01)$ & $(0.01)$ & $(0.01)$ & $(0.01)$ & $(0.01)$ & $(0.01)$ & $(0.06)$ & $(0.06)$ & $(0.06)$ \\
\hline \multirow[t]{2}{*}{$\mathrm{CZ}$ mean parental income } & 0.34 & 0.33 & 0.33 & 0.70 & 0.69 & 0.69 & 4.03 & 3.99 & 4.07 \\
\hline & $(0.04)$ & $(0.04)$ & $(0.04)$ & $(0.04)$ & $(0.04)$ & $(0.04)$ & $(0.26)$ & $(0.26)$ & $(0.25)$ \\
\hline \multirow[t]{2}{*}{$\mathrm{CZ}$ income transmission $(\theta)$} & -76 & -57 & -77 & -73 & -66 & -80 & -410 & -429 & -351 \\
\hline & (31) & (28) & (29) & $(28)$ & (24) & (25) & $(237)$ & $(220)$ & $(251)$ \\
\hline \multirow{2}{*}{$\begin{array}{l}\text { (Parental income }-\mathrm{CZ} \text { mean) } \\
\quad * \mathrm{CZ} \text { income transmission }(\theta)\end{array}$} & 0.64 & 0.61 & 0.59 & 0.41 & 0.27 & 0.19 & 2.35 & 2.45 & 1.54 \\
\hline & $(0.16)$ & $(0.16)$ & $(0.18)$ & $(0.17)$ & $(0.16)$ & $(0.18)$ & $(1.09)$ & $(1.07)$ & $(1.14)$ \\
\hline \multirow{2}{*}{$\begin{array}{l}\text { CZ mean parental income } \\
\quad * \mathrm{CZ} \text { income transmission }(\theta)\end{array}$} & 1.34 & 1.10 & 1.41 & 1.20 & 1.15 & 1.35 & 9.67 & 9.64 & 8.51 \\
\hline & $(0.61)$ & $(0.56)$ & $(0.55)$ & $(0.56)$ & $(0.49)$ & $(0.52)$ & $(4.73)$ & $(4.44)$ & $(4.96)$ \\
\hline \multirow{2}{*}{$\begin{array}{l}\text { SD of parental income random } \\
\text { coefficient }(\eta)\end{array}$} & 0.01 & 0.01 & 0.00 & 0.07 & 0.07 & 0.07 & 0.22 & 0.23 & 0.25 \\
\hline & $(0.02)$ & $(0.02)$ & $(0.01)$ & $(0.02)$ & $(0.02)$ & $(0.02)$ & $(0.13)$ & $(0.13)$ & $(0.13)$ \\
\hline \multicolumn{10}{|l|}{ Across-CZ distribution: } \\
\hline $\mathrm{SD}$ of $\mathrm{CZ}$ income transmission $(\theta)$ & 0.06 & 0.06 & 0.05 & 0.06 & 0.06 & 0.05 & 0.06 & 0.06 & 0.05 \\
\hline SD of p-outcome transmission $(\pi)$ & 0.04 & 0.04 & 0.03 & 0.07 & 0.07 & 0.07 & 0.25 & 0.27 & 0.27 \\
\hline \multirow[t]{2}{*}{ Coefficient of regression of $\theta$ on $\pi$} & 1.52 & 1.52 & 1.67 & 0.26 & 0.18 & 0.10 & 0.12 & 0.12 & 0.06 \\
\hline & $(0.37)$ & $(0.44)$ & $(0.49)$ & $(0.12)$ & $(0.11)$ & $(0.09)$ & $(0.11)$ & $(0.10)$ & $(0.06)$ \\
\hline $\mathrm{R}^{2}$ & 0.97 & 0.93 & 1.00 & 0.11 & 0.05 & 0.02 & 0.27 & 0.29 & 0.09 \\
\hline $\operatorname{Corr}(\theta, \pi)$ & 0.99 & 0.96 & 1.00 & 0.32 & 0.22 & 0.14 & 0.52 & 0.54 & 0.30 \\
\hline p-value, $\operatorname{SD}(\eta)=0$ (LR test $)$ & 0.92 & 0.82 & 0.99 & 0.00 & 0.00 & 0.00 & 0.33 & 0.36 & 0.26 \\
\hline
\end{tabular}

Notes: Columns 1, 4, and 7 correspond, respectively, to Table 8, column 1; Table 4, column 5; and Table 6, column 4. Columns 2, 5, and 8 use an alternative income transmission measure computed from the 1983-5 birth cohorts. Columns 3,6, and 9 use Chetty and Hendren's (forthcoming) "causal" measure based on children who move across CZs. 
Appendix Table A6. Intergenerational transmission in the ELS, with race and gender controls

\begin{tabular}{|c|c|c|c|c|c|c|c|c|c|}
\hline & \multicolumn{3}{|c|}{ Child income } & \multicolumn{3}{|c|}{$\begin{array}{l}\text { 12th grade math } \\
\text { score }\end{array}$} & \multicolumn{3}{|c|}{$\begin{array}{c}\text { Years of education } \\
\text { at } 26(* 100)\end{array}$} \\
\hline & $(1)$ & $(2)$ & (3) & (4) & $(5)$ & (6) & (7) & $(8)$ & (9) \\
\hline \multirow[t]{2}{*}{ Parental income - CZ mean } & 0.17 & 0.15 & 0.15 & 0.33 & 0.28 & 0.28 & 1.86 & 1.73 & 1.74 \\
\hline & $(0.01)$ & $(0.01)$ & $(0.01)$ & $(0.01)$ & $(0.01)$ & $(0.01)$ & $(0.06)$ & $(0.06)$ & $(0.06)$ \\
\hline \multirow[t]{2}{*}{$\mathrm{CZ}$ mean parental income } & 0.34 & 0.28 & 0.27 & 0.70 & 0.57 & 0.56 & 4.03 & 3.66 & 3.67 \\
\hline & $(0.04)$ & $(0.04)$ & $(0.04)$ & $(0.04)$ & $(0.04)$ & $(0.04)$ & $(0.26)$ & $(0.28)$ & $(0.28)$ \\
\hline \multirow[t]{2}{*}{$\mathrm{CZ}$ income transmission $(\theta)$} & -76 & -55 & -42 & -73 & -56 & -77 & -410 & -436 & -476 \\
\hline & $(31)$ & $(31)$ & (35) & (28) & (25) & (34) & $(237)$ & $(261)$ & $(277)$ \\
\hline (Parental income - CZ mean) & 0.64 & 0.45 & 0.40 & 0.41 & 0.13 & 0.22 & 2.35 & 1.95 & 2.20 \\
\hline * CZ income transmission $(\theta)$ & $(0.16)$ & $(0.15)$ & $(0.16)$ & $(0.17)$ & $(0.16)$ & $(0.18)$ & $(1.09)$ & $(0.96)$ & $(1.00)$ \\
\hline $\mathrm{CZ}$ mean parental income & 1.34 & 1.07 & 0.89 & 1.20 & 0.95 & 1.22 & 9.67 & 9.86 & 10.79 \\
\hline$* \mathrm{CZ}$ income transmission $(\theta)$ & $(0.61)$ & $(0.60)$ & $(0.63)$ & $(0.56)$ & $(0.51)$ & $(0.62)$ & $(4.73)$ & $(5.23)$ & $(5.44)$ \\
\hline \multirow[t]{2}{*}{ SD of parental income random coefficient $(\eta)$} & 0.01 & 0.00 & 0.00 & 0.07 & 0.06 & 0.06 & 0.22 & 0.17 & 0.17 \\
\hline & $(0.02)$ & $(0.02)$ & $(0.02)$ & $(0.02)$ & $(0.02)$ & $(0.02)$ & $(0.13)$ & $(0.15)$ & $(0.17)$ \\
\hline Race and gender & & $X$ & $X$ & & $\mathrm{X}$ & $\mathrm{X}$ & & $\mathrm{X}$ & $X$ \\
\hline Race and gender $X$ income transmission & & & $\mathrm{X}$ & & & $X$ & & & $X$ \\
\hline p-value, $\operatorname{SD}(\eta)=0$ (LR test $)$ & 0.92 & 0.96 & 0.96 & $<0.01$ & 0.02 & 0.02 & 0.33 & 0.18 & 0.19 \\
\hline
\end{tabular}

Notes: Columns 1, 4, and 7 correspond, respectively, to Table 8, column 1; Table 4, column 5; and Table 6, column 4. Columns 2, 5, and 8 add indicators for black, Hispanic, and female; columns 3, 6, and 9 also add interactions of these variables with CZ-level income transmission. Standard errors are clustered at the CZ level. Number of observations (rounded to the nearest 10) $=11,510$ for child income, 13,650 for 12 th grade test scores, and 13,250 for years of education. 
Appendix Table A7. Sensitivity of test score transmission to alternative scalings

\begin{tabular}{|c|c|c|c|c|c|}
\hline Scaling of parental income & \%ile & \%ile & \%ile & $\begin{array}{c}\log \\
\text { (income) }\end{array}$ & $\begin{array}{l}\text { Predicted } \\
\text { test score } \\
\% \text { ile }\end{array}$ \\
\hline \multirow[t]{2}{*}{ Scaling of child's test score } & \%ile & $\begin{array}{c}\mathrm{Z}- \\
\text { score } \\
(* 10) \\
\end{array}$ & $\begin{array}{c}\text { Predicted } \\
\text { earnings } \\
\% \text { ile } \\
\end{array}$ & \%ile & \%ile \\
\hline & (1) & (2) & (3) & (4) & (5) \\
\hline Parental income - CZ mean & $\begin{array}{c}0.33 \\
(0.01)\end{array}$ & $\begin{array}{c}0.11 \\
(0.00)\end{array}$ & $\begin{array}{c}0.08 \\
(0.00)\end{array}$ & $\begin{array}{c}2.28 \\
(0.08)\end{array}$ & $\begin{array}{c}0.85 \\
(0.03)\end{array}$ \\
\hline CZ mean parental income & $\begin{array}{c}0.70 \\
(0.04)\end{array}$ & $\begin{array}{c}0.24 \\
(0.01)\end{array}$ & $\begin{array}{c}0.16 \\
(0.01)\end{array}$ & $\begin{array}{c}5.26 \\
(0.27)\end{array}$ & $\begin{array}{c}1.79 \\
(0.09)\end{array}$ \\
\hline $\mathrm{CZ}$ income transmission $(\theta)$ & $\begin{array}{l}-72.6 \\
(27.8)\end{array}$ & $\begin{array}{l}-24.0 \\
(9.6)\end{array}$ & $\begin{array}{l}-18.0 \\
(7.2)\end{array}$ & $\begin{array}{l}-66.4 \\
(43.3)\end{array}$ & $\begin{array}{c}-152.8 \\
(65.8)\end{array}$ \\
\hline *(Parental income - CZ mean) & $\begin{array}{c}0.41 \\
(0.17)\end{array}$ & $\begin{array}{c}0.15 \\
(0.06)\end{array}$ & $\begin{array}{c}0.10 \\
(0.04)\end{array}$ & $\begin{array}{c}2.30 \\
(1.25)\end{array}$ & $\begin{array}{c}0.99 \\
(0.42)\end{array}$ \\
\hline * CZ mean parental income & $\begin{array}{l}1.20 \\
(0.56)\end{array}$ & $\begin{array}{c}0.39 \\
(0.19)\end{array}$ & $\begin{array}{c}0.30 \\
(0.14)\end{array}$ & $\begin{array}{c}6.03 \\
(4.06)\end{array}$ & $\begin{array}{c}2.81 \\
(1.34)\end{array}$ \\
\hline SD of parental income random coefficient $(\eta)$ & $\begin{array}{c}0.07 \\
(0.02)\end{array}$ & $\begin{array}{c}0.03 \\
(0.01)\end{array}$ & $\begin{array}{c}0.02 \\
(0.00)\end{array}$ & $\begin{array}{c}0.56 \\
(0.11)\end{array}$ & $\begin{array}{c}0.15 \\
(0.04)\end{array}$ \\
\hline \multicolumn{6}{|l|}{ Across-CZ distribution: } \\
\hline $\mathrm{SD}$ of $\mathrm{CZ}$ income transmission $(\theta)$ & 0.06 & 0.06 & 0.06 & 0.06 & 0.06 \\
\hline SD of parental income-test score transmission $(\pi)$ & 0.07 & 0.03 & 0.02 & 0.57 & 0.16 \\
\hline Coefficient of between-CZ regression of $\theta$ on $\pi$ & $\begin{array}{c}0.26 \\
(0.12)\end{array}$ & $\begin{array}{c}0.65 \\
(0.29)\end{array}$ & $\begin{array}{c}1.07 \\
(0.50)\end{array}$ & $\begin{array}{c}0.02 \\
(0.01)\end{array}$ & $\begin{array}{c}0.12 \\
(0.06)\end{array}$ \\
\hline $\mathrm{R}^{2}$ & 0.11 & 0.10 & 0.11 & 0.05 & 0.12 \\
\hline $\operatorname{Corr}(\theta, \pi)$ & 0.32 & 0.31 & 0.33 & 0.23 & 0.34 \\
\hline p-value, $\operatorname{SD}(\eta)=0 / \operatorname{corr}(\theta, \pi)=1$ (LR test) & $<0.01$ & $<0.01$ & $<0.01$ & $<0.01$ & 0.02 \\
\hline
\end{tabular}

Notes: Column 1 is from Table 4, column 5. See notes to Table 4 for details. Subsequent columns vary the scaling of the dependent variable (the 12th grade math score) or the parental income measure. Number of observations (rounded to the nearest 10) ranges from 13,590 to 13,650. 
Appendix Table A8. Transmission of parental income to children's non-cognitive skills

\begin{tabular}{|c|c|c|c|c|c|c|}
\hline & $\begin{array}{c}\text { Parental } \\
\text { income }\end{array}$ & $\begin{array}{c}\text { Parental } \\
\text { income * } \\
\text { CZ income } \\
\text { transmission }\end{array}$ & $\begin{array}{l}\text { SD of parental } \\
\text { income } \\
\text { random } \\
\text { coefficient }(\eta)\end{array}$ & $\operatorname{Corr}(\theta, \pi)$ & $\begin{array}{l}\text { Coefficient } \\
\text { of } \\
\text { regression } \\
\text { of } \theta \text { on } \pi \\
\end{array}$ & $\begin{array}{c}\mathrm{p} \text {-value, } \\
\text { LR test of } \\
\operatorname{SD}(\eta)=0\end{array}$ \\
\hline & $(1)$ & $(2)$ & (3) & $(4)$ & $(5)$ & $(6)$ \\
\hline \multicolumn{7}{|l|}{ Panel A: ELS (10th grade) } \\
\hline Instrumental motivation & $\begin{array}{c}0.09 \\
(0.01)\end{array}$ & $\begin{array}{c}0.07 \\
(0.16)\end{array}$ & $\begin{array}{c}0.03 \\
(0.01)\end{array}$ & 0.16 & $\begin{array}{c}0.36 \\
(0.74)\end{array}$ & 0.26 \\
\hline General effort and persistence & $\begin{array}{c}0.09 \\
(0.01)\end{array}$ & $\begin{array}{l}-0.05 \\
(0.21)\end{array}$ & $\begin{array}{l}0.06 \\
(0.02)\end{array}$ & -0.05 & $\begin{array}{l}-0.05 \\
(0.23)\end{array}$ & 0.02 \\
\hline General control beliefs & $\begin{array}{c}0.14 \\
(0.01)\end{array}$ & $\begin{array}{l}-0.23 \\
(0.19)\end{array}$ & $\begin{array}{l}0.05 \\
(0.02)\end{array}$ & -0.24 & $\begin{array}{l}-0.25 \\
(0.28)\end{array}$ & $<0.01$ \\
\hline Self-efficacy - Math & $\begin{array}{c}0.11 \\
(0.01)\end{array}$ & $\begin{array}{c}0.16 \\
(0.14)\end{array}$ & $\begin{array}{c}0.03 \\
(0.01)\end{array}$ & 0.31 & $\begin{array}{c}0.61 \\
(0.66)\end{array}$ & 0.21 \\
\hline Self-efficacy - Reading & $\begin{array}{l}0.14 \\
(0.01)\end{array}$ & $\begin{array}{l}-0.45 \\
(0.23)\end{array}$ & $\begin{array}{l}0.07 \\
(0.02)\end{array}$ & -0.37 & $\begin{array}{l}-0.30 \\
(0.25)\end{array}$ & 0.02 \\
\hline Index of five measures & $\begin{array}{c}0.14 \\
(0.01)\end{array}$ & $\begin{array}{l}-0.16 \\
(0.18)\end{array}$ & $\begin{array}{l}0.05 \\
(0.02)\end{array}$ & -0.19 & $\begin{array}{l}-0.21 \\
(0.28)\end{array}$ & $<0.01$ \\
\hline \multicolumn{7}{|c|}{ Panel B: ECLS-K 5th grade student survey } \\
\hline $\begin{array}{l}\text { Perceived interest / competence } \\
\text { in reading }\end{array}$ & $\begin{array}{l}0.05 \\
(0.01)\end{array}$ & $\begin{array}{l}-0.18 \\
(0.21)\end{array}$ & $\begin{array}{l}0.05 \\
(0.01)\end{array}$ & -0.21 & $\begin{array}{l}-0.23 \\
(0.28)\end{array}$ & $<0.01$ \\
\hline $\begin{array}{l}\text { Perceived interest / competence } \\
\text { in math }\end{array}$ & $\begin{array}{l}0.02 \\
(0.01)\end{array}$ & $\begin{array}{l}0.07 \\
(0.16)\end{array}$ & $\begin{array}{l}0.04 \\
(0.02)\end{array}$ & 0.11 & $\begin{array}{l}0.17 \\
(0.45)\end{array}$ & 0.44 \\
\hline $\begin{array}{l}\text { Perceived interest / competence } \\
\text { in all school subjects }\end{array}$ & $\begin{array}{l}0.08 \\
(0.01)\end{array}$ & $\begin{array}{c}0.11 \\
(0.21)\end{array}$ & $\begin{array}{l}0.05 \\
(0.01)\end{array}$ & 0.13 & $\begin{array}{c}0.14 \\
(0.27)\end{array}$ & 0.04 \\
\hline $\begin{array}{l}\text { Perceived interest / competence } \\
\text { in peer relations }\end{array}$ & $\begin{array}{c}0.07 \\
(0.01)\end{array}$ & $\begin{array}{l}-0.34 \\
(0.17)\end{array}$ & $\begin{array}{c}0.04 \\
(0.02)\end{array}$ & -0.45 & $\begin{array}{l}-0.59 \\
(0.50)\end{array}$ & 0.10 \\
\hline Externalizing problem behaviors & $\begin{array}{c}0.19 \\
(0.01)\end{array}$ & $\begin{array}{c}0.03 \\
(0.12)\end{array}$ & $\begin{array}{c}0.01 \\
(0.01)\end{array}$ & 0.19 & $\begin{array}{c}1.41 \\
(8.11)\end{array}$ & 0.85 \\
\hline Internalizing problem behaviors & $\begin{array}{c}0.18 \\
(0.01)\end{array}$ & $\begin{array}{l}-0.39 \\
(0.17)\end{array}$ & $\begin{array}{c}0.05 \\
(0.01)\end{array}$ & -0.41 & $\begin{array}{l}-0.42 \\
(0.23)\end{array}$ & $<0.01$ \\
\hline Index of six measures & $\begin{array}{c}0.20 \\
(0.01)\end{array}$ & $\begin{array}{l}-0.26 \\
(0.17)\end{array}$ & $\begin{array}{c}0.03 \\
(0.02)\end{array}$ & -0.43 & $\begin{array}{l}-0.72 \\
(0.86)\end{array}$ & 0.17 \\
\hline
\end{tabular}

Table continued on next page 


\begin{tabular}{|c|c|c|c|c|c|c|}
\hline & $\begin{array}{c}\text { Parental } \\
\text { income }\end{array}$ & $\begin{array}{c}\text { Parental } \\
\text { income * } \\
\text { CZ income } \\
\text { transmission }\end{array}$ & $\begin{array}{l}\text { SD of parental } \\
\text { income } \\
\text { random } \\
\text { coefficient }(\eta) \\
\end{array}$ & $\operatorname{Corr}(\theta, \pi)$ & $\begin{array}{c}\text { Coefficient } \\
\text { of } \\
\text { regression } \\
\text { of } \theta \text { on } \pi \\
\end{array}$ & $\begin{array}{l}\text { p-value, } \\
\text { LR test of } \\
\operatorname{SD}(\eta)=0\end{array}$ \\
\hline & $(1)$ & (2) & (3) & $(4)$ & $(5)$ & $(6)$ \\
\hline \multicolumn{7}{|c|}{ Panel C: ECLS-K 5th grade teacher survey } \\
\hline Approaches to learning & $\begin{array}{l}0.19 \\
(0.01)\end{array}$ & $\begin{array}{c}0.58 \\
(0.18)\end{array}$ & $\begin{array}{c}0.06 \\
(0.02)\end{array}$ & 0.51 & $\begin{array}{c}0.44 \\
(0.20)\end{array}$ & 0.02 \\
\hline Self-control & $\begin{array}{c}0.15 \\
(0.01)\end{array}$ & $\begin{array}{c}0.72 \\
(0.18)\end{array}$ & $\begin{array}{c}0.06 \\
(0.02)\end{array}$ & 0.57 & $\begin{array}{c}0.45 \\
(0.20)\end{array}$ & 0.01 \\
\hline Interpersonal skills & $\begin{array}{c}0.15 \\
(0.01)\end{array}$ & $\begin{array}{c}0.22 \\
(0.17)\end{array}$ & $\begin{array}{c}0.05 \\
(0.02)\end{array}$ & 0.25 & $\begin{array}{c}0.28 \\
(0.21)\end{array}$ & 0.16 \\
\hline $\begin{array}{l}\text { Peer relations (self-control \& } \\
\text { interpersonal) }\end{array}$ & $\begin{array}{l}0.15 \\
(0.01)\end{array}$ & $\begin{array}{l}0.52 \\
(0.18)\end{array}$ & $\begin{array}{l}0.06 \\
(0.01)\end{array}$ & 0.50 & $\begin{array}{l}0.47 \\
(0.20)\end{array}$ & 0.03 \\
\hline Externalizing problem behaviors & $\begin{array}{c}0.11 \\
(0.01)\end{array}$ & $\begin{array}{l}0.48 \\
(0.12)\end{array}$ & $\begin{array}{l}0.03 \\
(0.02)\end{array}$ & 0.70 & $\begin{array}{l}1.03 \\
(0.60)\end{array}$ & 0.05 \\
\hline Internalizing problem behaviors & $\begin{array}{c}0.11 \\
(0.01)\end{array}$ & $\begin{array}{l}-0.02 \\
(0.20)\end{array}$ & $\begin{array}{c}0.07 \\
(0.01)\end{array}$ & -0.01 & $\begin{array}{l}-0.01 \\
(0.16)\end{array}$ & $<0.01$ \\
\hline Index of six measures & $\begin{array}{c}0.21 \\
(0.01)\end{array}$ & $\begin{array}{c}0.59 \\
(0.21)\end{array}$ & $\begin{array}{c}0.07 \\
(0.02)\end{array}$ & 0.47 & $\begin{array}{c}0.37 \\
(0.15)\end{array}$ & 0.02 \\
\hline
\end{tabular}

Notes: Each row presents a single mixed model regression, estimated without sampling weights. Dependent variables are discrete responses, scaled so that higher numbers are better and then converted to percentiles between 0 and 100 (with discrete responses assigned to the midpoint of the relevant range). Indexes are constructed by reversing the original response scale as necessary, converting to z-scores, averaging across responses and then converting to percentiles. Parental incomes in columns 1-3 are deviated from the CZ mean. Standard errors are clustered at the CZ level. 